\title{
The Red Sea: A Natural Laboratory for Wind and Wave Modeling
}

\author{
SABIQUE LANGODAN \\ King Abdullah University of Science and Technology, Physical Science and Engineering Division, \\ Thuwal, Saudi Arabia \\ LUIGI CAVALERI \\ Institute of Marine Sciences, Venice, Italy \\ YESUBABU VISWANADHAPALLI AND IBRAHIM HOTEIT \\ King Abdullah University of Science and Technology, Physical Science and Engineering Division,
} Thuwal, Saudi Arabia

(Manuscript received 6 November 2013, in final form 20 August 2014)

\begin{abstract}
The Red Sea is a narrow, elongated basin that is more than $2000 \mathrm{~km}$ long. This deceivingly simple structure offers very interesting challenges for wind and wave modeling, not easily, if ever, found elsewhere. Using standard meteorological products and local wind and wave models, this study explores how well the general and unusual wind and wave patterns of the Red Sea could be reproduced. The authors obtain the best results using two rather opposite approaches: the high-resolution Weather Research Forecasting (WRF) local model and the slightly enhanced surface winds from the global European Centre for Medium-Range Weather Forecasts model. The reasons why these two approaches produce the best results and the implications on wave modeling in the Red Sea are discussed. The unusual wind and wave patterns in the Red Sea suggest that the currently available wave model source functions may not properly represent the evolution of local fields. However, within limits, the WAVEWATCH III wave model, based on Janssen's and also Ardhuin's wave model physics, provides very reasonable results in many cases. The authors also discuss these findings and outline related future work.
\end{abstract}

\section{The general problem}

Large-scale meteorological models nowadays produce high-quality results. As an example, when compared with locally measured data, the $10-\mathrm{m}$ wind speeds from the European Centre for Medium-Range Weather Forecasts (ECMWF; Reading, United Kingdom) model have a bias of less than $0.02 \mathrm{~m} \mathrm{~s}^{-1}$ with a 0.15 scatter index or less (Richardson et al. 2013). These are, however, global results, dominated by the performance of the world's oceans. When we focus our attention on land-affected areas or, in particular, the world's inner seas, the situation is less favorable (see, among others,

Corresponding author address: Ibrahim Hoteit, 4700 King Abdullah University of Science and Technology, Physical Science and Engineering Division, Mail box 1184, Thuwal 23955-6900, Saudi Arabia. E-mail: ibrahim.hoteit@kaust.edu.sa
Bertotti et al. 2013; Ponce de Leon and Guedes Soares 2008). Experience indicates that in general the smaller the basin, the poorer the models perform, especially if the basin is surrounded by a complex orography.

Being wind driven, wind waves follow accordingly. Their high sensitivity to even small variations in the input wind field can be interpreted from two opposite points of view. On one hand (pessimistic), the errors we must expect in the resulting wave fields are larger. A $10 \%$ error in wind speed roughly corresponds to a $20 \%$ error of the significant wave height in a well-developed sea. On the other hand (optimistically), when compared with measured data, waves offer, within limits, a direct verification of the quality of the driving winds.

Here, we analyze this kind of situation and discuss the quality of the different solutions used for wind and wave modeling by considering wind and wave patterns in the Red Sea, an area providing a special example with peculiar 
characteristics. The Red Sea is characterized by highly varying and multifaceted wind and wave patterns, which may stretch to the limit some aspects of the usual wind and wave modeling approach.

Our paper is organized as follows: We begin with a detailed description of the area (section 2) and of the available data (section 3). In section 4 , we describe our modeling approaches and the period of study. We present the results in section 5. Section 6 concludes the paper with a discussion of the obtained results and an outline for future research.

\section{The Red Sea}

\section{a. Geology and orography}

The tectonic split between the African (Nubian) and Arabian plates, along the East African Rift, gave rise during the last 25 million years to what is now known as the Red Sea basin [Fig. 1; see Waltham (2005) and, for general information, the recent paper by Ralston et al. (2013)]. The basin covers the area $12^{\circ}-30^{\circ} \mathrm{N}$ and $34^{\circ}-$ $43^{\circ} \mathrm{E}$. It is $2250 \mathrm{~km}$ long, from the Suez and Aqaba narrow gulfs in the north to the southern strait of Bab el Mandeb connecting the Red Sea with the Indian Ocean.

The geological genesis established both the submerged and surrounding characteristics of the Red Sea. In the northern section, apart from the two gulfs, the bottom deepens directly from the coast with a very narrow coastal shallow area. In the meridional part, the deepening is more gradual with larger coastal shallow zones. The overall average depth is about $490 \mathrm{~m}$, with peak values larger than $2000 \mathrm{~m}$ (Morcos 1970).

On the coast, mountain ranges border the Red Sea on both sides, at most a few tens of kilometers inland, peaking on the eastern shore at more than $2000 \mathrm{~m}$ on the Arabian Peninsula to the south and on the western shore at more than $4500 \mathrm{~m}$ above the extensive Ethiopian Plateau. This orography has a profound influence on the local dominant wind regimes, which are specified as the winter and summer seasons. High mountains are present along the Sinai Peninsula as well, peaking at the historical Mount Sinai, $2285 \mathrm{~m}$ high, and Mount St. Catherine, $2629 \mathrm{~m}$ high, the highest peak in Egypt.

\section{b. Winds}

In summer (Fig. 2a; see also Ralston et al. 2013), that is, from April until October, an almost permanent northnorthwest (NNW) wind blows along the whole length of the sea, with speeds close to $10 \mathrm{~m} \mathrm{~s}^{-1}$ and frequently exceeding $15 \mathrm{~m} \mathrm{~s}^{-1}$. At the southern strait, the wind typically turns left, merging with the Indian Ocean southwest (SW) monsoon. In winter (Fig. 2c), the same northerly wind dominates the northern part of the basin,

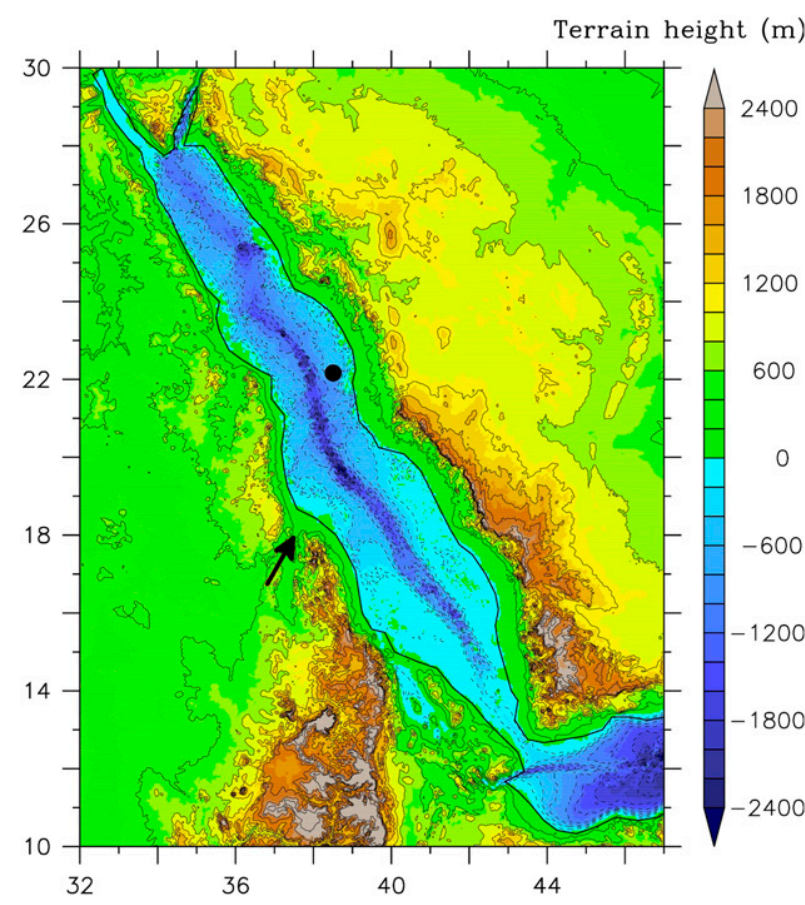

FIG. 1. Orography and bathymetry of the Red Sea basin. The black dot shows the position of the instrumented buoy active during the study period. Arrow indicates the location of the Tokar Gap.

generally until about $18^{\circ} \mathrm{N}$. South of this latitude, a south-southeast (SSE) wind prevails, associated with the northeast (NE) monsoon in the Indian Ocean that turns right through the Bab el Mandeb strait. The convergence of the NNW and SSE winds at $18^{\circ} \mathrm{N}$ leads to a local zone, characterized by a cloudy sky and drizzle in contrast with the ubiquitous clear weather typical of the area. September and May are transitional months with lighter winds. The classical northern storm belt acts far to the north of the Red Sea, with the Gulf of Suez the only area affected by Mediterranean storms from which the already typical northerly winds may be strengthened.

The orography surrounding the basin, with larger and smaller valleys cut across the bordering mountain ridges, leads to typical winds that are relevant for characterizing the local wind regimes. The most unusual and relevant one is the wind passing through the Tokar Gap (see Fig. 2b). This $110-\mathrm{km}$-wide valley is located in the Red Sea Hills, at about $18^{\circ} \mathrm{N}$, on the African side. In summer, night cooling over the inland Sudan Boma Plateau leads to a negative pressure gradient toward the sea. The ensuing eastward wind is strengthened by the katabatic effect, peaking in the early part of the day with speeds often above $15 \mathrm{~m} \mathrm{~s}^{-1}$. These winds spread across the Red Sea, frequently reaching the opposite east coast. During the day, an opposite wind, in principle associated with the heating of the Red Sea Hills, does not appear because of the summer 

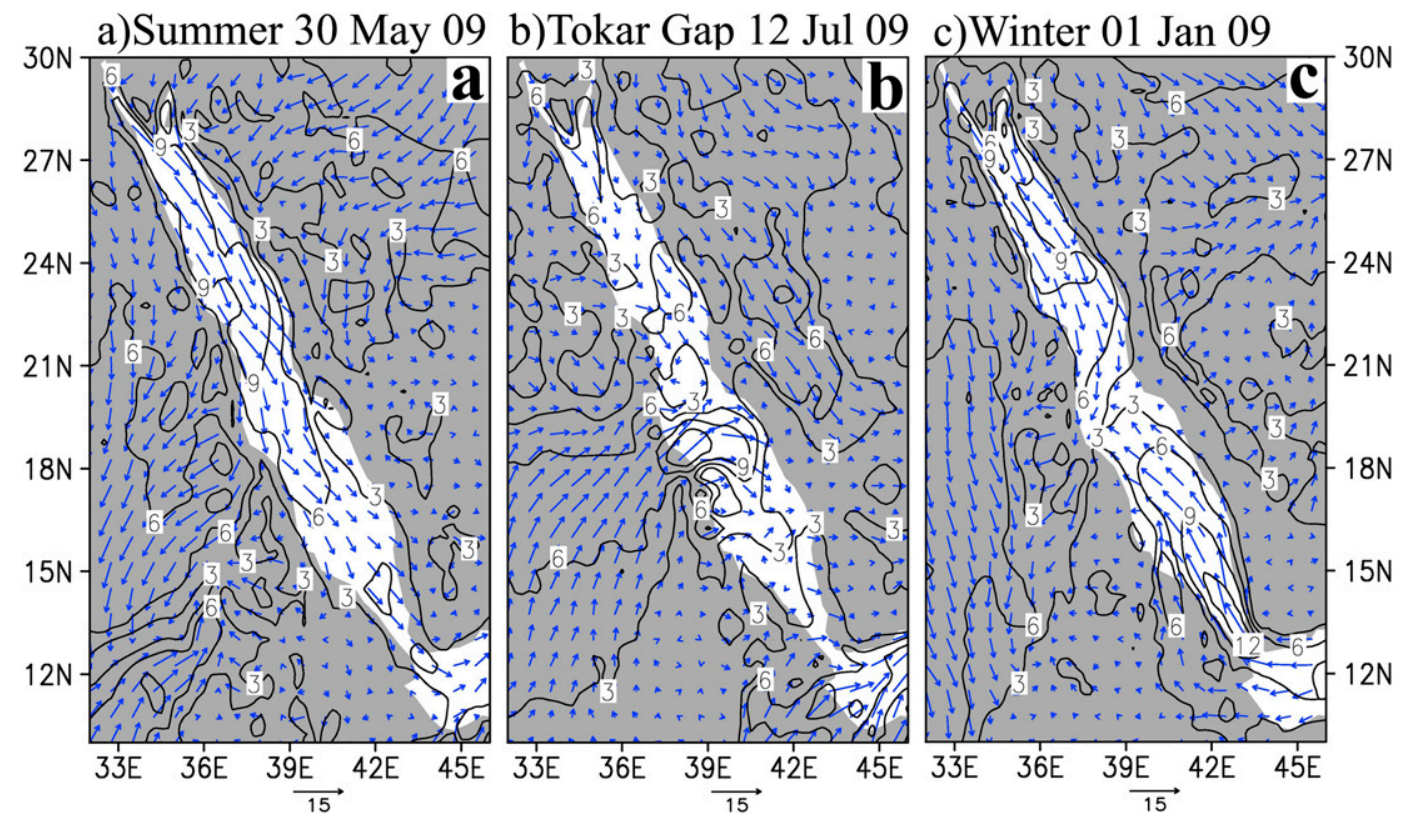

FIG. 2. Three typical meteorological situations in the Red Sea. (a) The NNW flow affecting the whole basin, (b) Tokar Gap wind cutting across the NNW flow, and (c) the NNW flow- and monsoon-induced SSE wind in the southern part of the basin impinging on each other at the center of the Red Sea. Isotachs at $3 \mathrm{~m} \mathrm{~s}^{-1}$ interval.

position of the intertropical convergence zone (ITCZ; see, e.g., Jiang et al. 2009), which in this period moves as far north as the Tokar Gap. Also because of the influence of orography, the ensuing eastward wind prevails over the "gap sea breeze," leading to a homogeneous flow in the easterly direction. During the early morning, the ITCZassociated winds contribute to strengthen the eastwarddirected winds. Figure 3 a provides a close-up view of the general wind situation during a Tokar Gap event.

In winter, an opposite, although milder, flow appears, also in connection with the convergence zone at $18^{\circ} \mathrm{N}$. The two converging winds from the NNW and the SSE (see Fig. 2c), besides overlapping with each other (which leads to the local clouds and drizzle), lead to a turning west wind, exiting the basin through the gap.

Narrower, but frequent gaps are also present along the east coast (see Fig. 1), leading to narrow, westwardblowing jets. Contrary to the winds in the Tokar Gap, these jets are related to the overall synoptic situation. They appear mainly in winter, at 10- to 30-day intervals, and they generally last 2 or 3 days. Their speed can reach up to $15 \mathrm{~m} \mathrm{~s}^{-1}$. A characteristic of these jets is their katabatic compression with a substantial increase in the air temperature $\left(+10^{\circ}-15^{\circ} \mathrm{C}\right.$; see Jiang et al. 2009). In a way, these jets are similar to the better-known phenomenon of the bora winds on the Croatian coast of the Adriatic Sea (Pielke 2002), which do not share the temperature gradient. Figure $3 \mathrm{~b}$ shows an example of the westward winter jets over the Red Sea.
Finally, to characterize the local wind environment of the Red Sea completely, particularly in the coastal areas, due attention must be paid to the sea and land breezes. In general, sea breezes are strong because of the high land-sea temperature differences during the day.

\section{c. Oceanography}

The maximum tidal excursion is $0.6 \mathrm{~m}$ in the north and $0.9 \mathrm{~m}$ in the south, with virtually no variations in the central part of the basin (Encyclopedia Britannica 2008). The circulation in the Red Sea is mainly associated with the local winds and with the strong evaporation rate with consequent buoyancy loss and a net inflow at the Bab el Mandeb strait. Despite recent studies (Yao et al. 2014a,b), no detailed information is available about Red Sea currents. Ralston et al. (2013) extensively discuss the possibility of coupling waves and currents in their simulation of Red Sea conditions. They conclude that the general low values of the currents are not expected to affect the simulated wave conditions at an appreciable level. We therefore do not consider the effect of currents here.

Little is known about the wave conditions in the Red Sea. Only recently, Ralston et al. (2013) presented an initial description of local wind and waves. Generally speaking and in reference to the maps in Fig. 2, it is natural to suggest that waves are mainly associated with the dominant wind regimes; they mainly move southward in summer, while they converge toward the center 

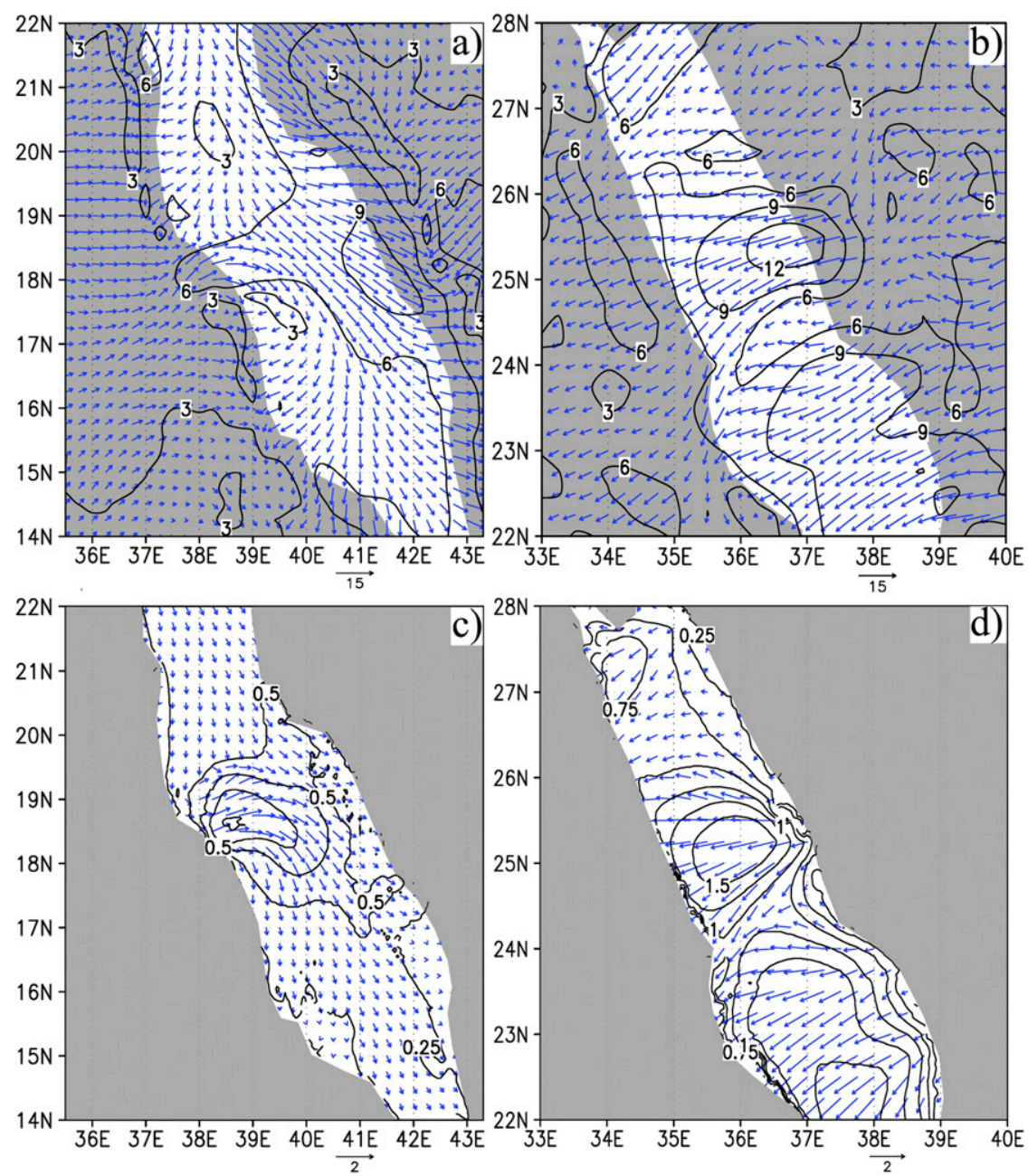

FIG. 3. Two typical (top) wind and (bottom) wave situations in the Red Sea. (a),(c) Tokar gap jet impinging on the NNW flow; (b),(d) easterly jets from the Arabian valleys. Isolines at $3 \mathrm{~m} \mathrm{~s}^{-1}$ and $0.25-\mathrm{m}$ intervals, respectively.

of the basin in winter. This seemingly ordered pattern is substantially disrupted by the various transversal jets mentioned above (from the Tokar Gap on the Sudan coast and the various smaller jets on the Arabian Peninsula) that may lead to locally enhanced wave heights. Figures $3 \mathrm{c}$ and $3 \mathrm{~d}$ provide examples of the wave fields under the influence of transversal jets. The wave conditions are particularly interesting in the $18^{\circ} \mathrm{N}$ convergence zone, where waves from opposite directions collide. The wind speeds are not very strong, with typical maxima around $15 \mathrm{~m} \mathrm{~s}^{-1}$. However, associated with the extensive north-south (N-S) fetch, even these relatively mild winds can nevertheless give rise to substantial wave conditions.

\section{Available measured data}

In the latter years of the first decade of the twenty-first century, an agreement between King Abdullah University of Science and Technology (KAUST; located on the Arabian coast, about $100 \mathrm{~km}$ north of Jeddah) and Woods Hole Oceanographic Institution (WHOI; Woods Hole, Massachusetts) led to the deployment of a meteooceanographic buoy in the Red Sea at a position about $22^{\circ} 10^{\prime} \mathrm{N}, 38^{\circ} 30^{\prime} \mathrm{E}$ shown with a black dot in Fig. 1 with a local depth of $693 \mathrm{~m}$. The buoy was operational from October 2008 to May 2010, providing the standard meteorological parameters plus surface wave information. These data were collected at hourly intervals. No data about currents were collected. Because the anemometer was $4 \mathrm{~m}$ above the sea surface, all the wind data were corrected to $10 \mathrm{~m}$ above the sea surface by assuming neutral stability conditions. Here, we consider data from a full calendar year, that is, the period 1 January through 31 December 2009.

Aside from the data provided by the buoy, no further surface-measured data are available from the Red Sea. 
Meteorological data collected along the coasts are scarce, and, in any case, not representative of open sea conditions. Hence, we utilized remotely sensed data. For wave heights, we used the quality-controlled and calibrated altimeter-derived values from the GlobWave database (see http://globwave.ifremer.fr/). The GlobWave project has carried out extensive validation on the product and is summarized in the validation reports available on the GlobWave website (http:// globwave.ifremer.fr/validation). We further verified with the corresponding ones from the Radar Altimeter Database System (RADS; http://rads.tudelft.nl/rads/ rads.shtml). For wind information, we used the data derived from the Advanced Scatterometer (ASCAT; http://podaac.jpl.nasa.gov). ASCAT wind data have a nominal accuracy of $1.2 \mathrm{~m} \mathrm{~s}^{-1}$ and $18^{\circ}$ between 4 and $24 \mathrm{~m} \mathrm{~s}^{-1}$ wind speed (Bentamy et al. 2008; Verhoef and Stoffelen 2013). Vogelzang et al. (2011) reported an even better accuracy. This is certainly accurate enough for this study. For further verification of the ASCAT data in a narrow enclosed sea, we compared these data with the buoy data (with 30-min and 25-km allowance). The resulting scatter diagram is presented in Fig. 4. The color bar indicates the density (normalized) of points in each pixel. The best-fit slope of 1.01 and a scatter index of 0.14 (see appendix $\mathrm{C}$ for its definition) are certainly reassuring for the use of the ASCAT data in the Red Sea.

\section{Numerical modeling}

In modeling the wind and wave conditions in the Red Sea, we followed several approaches. On this we differ from the approach followed by Ralston et al. (2013), who, having selected one wind model and one wave model, reported and discussed the derived results. Our aim is to find which approach could be considered the most appropriate one, especially for wave modeling, both in the long term and in specific situations. We stress that under some conditions, for example, the Tokar Gap, the unusual conditions of the Red Sea may cause the "generally best" approach to fail, with respect to another one. The five approaches we used were as follows:

(i) The National Oceanic and Atmospheric Administration-National Centers for Environmental and Climate Prediction (NOAA-NCEP) Final Analysis (NCEP). These winds are available on a $1^{\circ}$ grid and at 6-h intervals $(0000,0600,1200$, and 1800 UTC).

(ii) ECMWF daily global analysis. In 2009, the spectral resolution was TL799, corresponding to a spatial resolution of about $25 \mathrm{~km}$. The data, surface winds in particular, were available at 6 -h intervals $(0000$, 0600, 1200, and 1800 UTC).

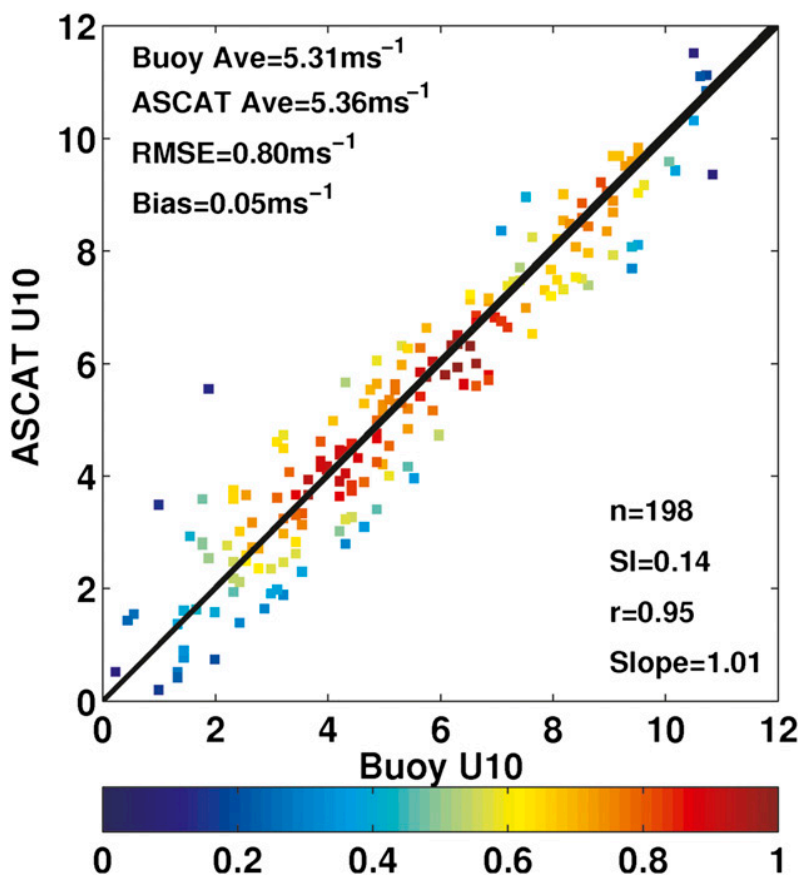

FIG. 4. Scatter diagram of scatterometer wind speeds vs buoy data. The color bar indicates the density (normalized) of points in each pixel.

(iii) The NCEP Final Analysis data were used to initialize and as boundary conditions for the advanced dynamical core version of the Weather Research and Forecasting (WRF) model (Skamarock et al. 2008). WRF is a state-of-the-art nonhydrostatic model amply described in the literature. A summary description of the chosen version, together with the details of the implementation, is given in appendix A. For our purposes, the WRF wind fields were available at $10 \mathrm{~km}$ and at 3-h intervals.

(iv) WRF analysis, a high-resolution local model at 10-km resolution and 3-h intervals assimilating conventional observations from surface stations, upper-air soundings, and satellite observations. The corresponding details of the implementation are in appendix B.

(v) Enhanced ECMWF wind speeds. We follow the experience of Cavaleri and Bertotti (1997) and Bertotti et al. (2011) in the Adriatic Sea. This sea, to the east of Italy, between the peninsula and the Balkans, exhibits on a smaller dimension many of the features of the Red Sea, with similar oblique elongated geometry and surrounding orography. In this area, the ECMWF analysis and forecast data were found to be correct for the structure, but the moduli were low. Very good results were achieved, especially for the derived wave fields, by simply increasing the wind moduli by a fixed percentage. This was determined on the basis of comparison 
with scatterometer, altimeter, and buoy data. A similar procedure has been followed for the Red Sea.

In using these five different approaches we pursued a double aim: 1) explore how the quality of the results (wind and waves) depends on the resolution of the available data and 2) explore the possibility of using the $1^{\circ}$ NCEP data (approach iii) above) as initial and boundary conditions to force a high-resolution model. Granted, an expected deterioration of the model performance when using the coarser data, we wished to quantify the respective available final information. For an easier reference and to stress the implications of the different resolutions in tests, we will refer to the five approaches listed above respectively as (i) $1 \mathrm{deg}$, (ii) EC, (iii) WRF-forecast (WRF-FC), (iv) WRF analysis (WRF-AN), and (v) EC+.

For wave modeling, we used WAVEWATCH III (referred to as WW3; Tolman 1999, 2002), an advanced third-generation wave model amply described in the literature. WW3 (version v3.14) is implemented on a regular latitude-longitude grid with $0.05^{\circ}$ resolution covering the whole Red Sea from $10^{\circ}$ to $30^{\circ} \mathrm{N}, 31^{\circ}$ to $50^{\circ} \mathrm{E}$. We used high-resolution bathymetry from the 1-min gridded elevations/bathymetry for the world (ETOPO1) database available from the National Geophysical Data Centre (NGDC, United States). The model setup we used has 33 frequencies, starting from $0.05 \mathrm{~Hz}$ with 1.1 geometric progressions and 24 equally spaced directions. We also tested a higher directional resolution (36 directions), but without any significant difference. The outputs are available at 1-h intervals. Besides the standard integrated parameters at all grid points, 2D spectra were saved at a few points and along the axis of the basin. Following the evolution of the WW3 model, after some trial and error with the physics package of Tolman and Chalikov (1996), we changed to the one by Janssen $(1991,2008)$ with the modified dissipation source term proposed by Bidlot et al. (2007), referred to as BJA. Following our first analysis of the results, we also repeated the tests using the physics of Ardhuin et al. (2010). The results were practically the same. More detailed information about WW3 can be found in the Tolman (2008).

The time and spatial resolutions of the considered sources and models are summarized in Table 1. For each of the five considered sources, we ran the wave model for the full year of 2009 .

\section{Results}

In this section, we provide basic results and related statistics for the five meteorological approaches considered here. Moving progressively from the general to
TABLE 1. Resolution of the meteorological and the WAVEWATCH III wave models.

\begin{tabular}{cccc}
\hline \hline NCEP & WRF & ECMWF & WAVEWATCH III \\
\hline $1^{\circ}, 6 \mathrm{~h}$ & $10 \mathrm{~km}, 3 \mathrm{~h}$ & $25 \mathrm{~km}, 6 \mathrm{~h}$ & $0.05^{\circ}, 33$ freq, 24 directions \\
\hline
\end{tabular}

the specific, we first analyze the general performance for wind and waves in terms of both validation statistics and data covering the whole year. Then we provide a more detailed assessment of the performance of the wind and wave models for the distinct patterns found in the Red Sea (the NNW winds covering the entire basin, Tokar Gap winds, converging waves, and easterly jets) when enough data are available to develop robust statistics. The results are then discussed in section 6.

\section{a. Modeling the events and validation}

We show in Fig. 5 the general performance of the first four (Figs. 5a-d) approaches listed above. We compare the simulated fields from the models with the scatterometer and altimeter data on wind speed $U_{10}$ and significant wave height $H_{s}$, respectively. The model fields, when possible, are interpolated to the scatterometer and altimeter observation locations with a 30-min allowance for waves and a 1-h allowance for winds. The dataset consists of 23237 pairs (604 passes) for altimeter readings and 68387 (424 passes) pairs for scatterometer readings. The various panels show the corresponding scatter diagrams, with the colors representing the number of cases in each pixel.

Looking first at wind (left panels), we see that all the models provide reasonable results, but with a marked underestimate by $1 \mathrm{deg}$. The other three models are, as best-fit line, only slightly different from unity. There is a substantial spread by all the models, larger in $1 \mathrm{deg}$ and WRF-FC. With the exception of WRF-FC, the asymmetry of the distributions suggests a tendency toward an underestimate of the larger values. The overall statistics are summarized in Table 2. See appendix $\mathrm{C}$ for the definition of the various statistical parameters.

As expected, the wave results (right panels in Fig. 5) follow accordingly, with a more marked underestimate of the significant wave height. The exception is WRF-FC, which we shall discuss in the next section. There is a substantial scatter with some grouping evident, suggesting different performance of the models in specific situations. Here too, the overall statistics are given in Table 2.

The only surface-measured data are available from the buoy that was moored at the position marked (black dot) in Fig. 1. While logistically convenient, the position was not optimal for general verification because it is well off the main axis of the basin and partially shielded with 

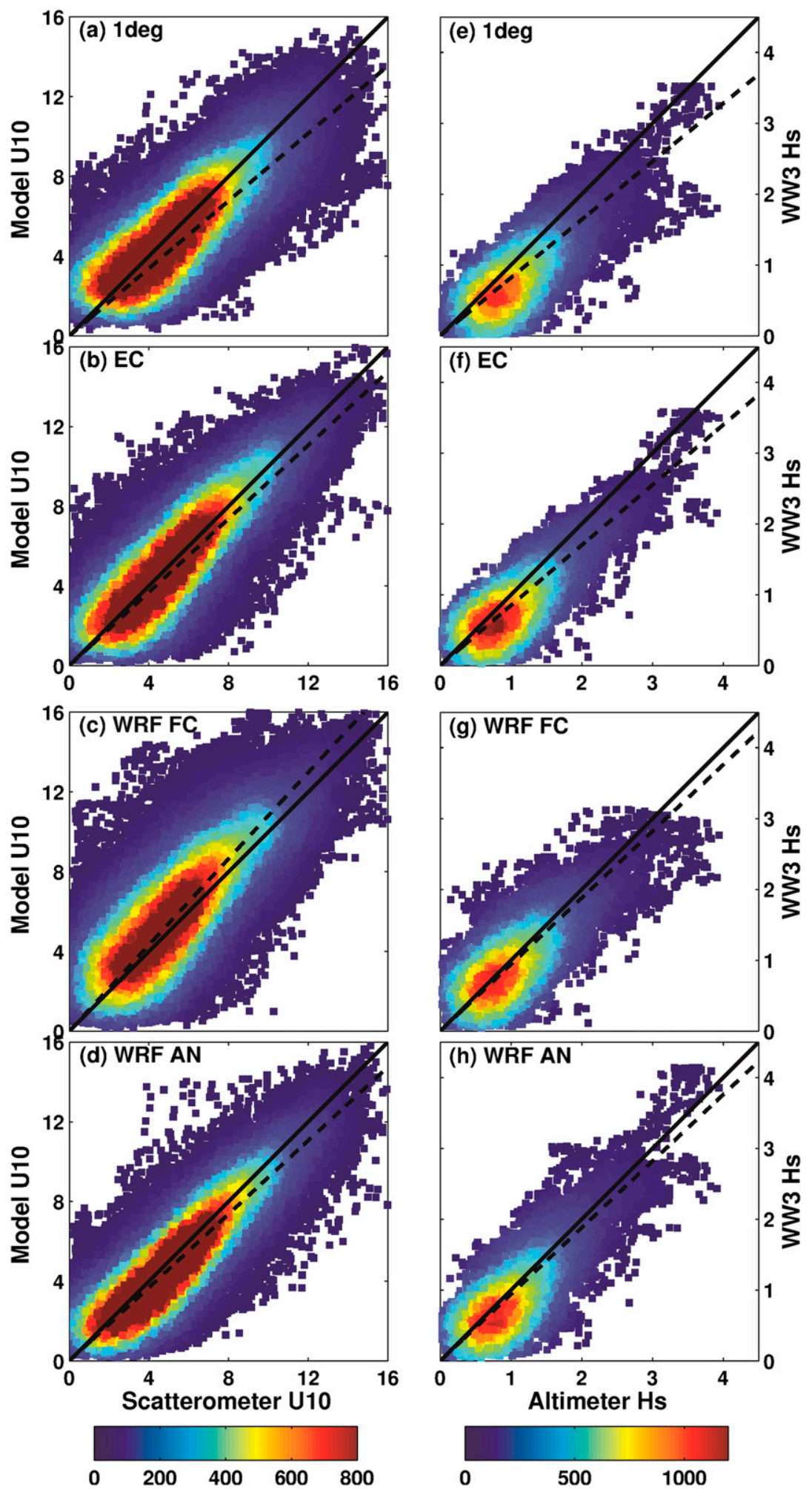

FIG. 5. Scatter diagrams and best fits for four of the considered meteorological model winds (1deg EC, WRF-FC, and WRF-AN) and derived wave heights (using the WAVEWATCH III model). The comparison is against respectively ASCAT scatterometer and altimeters (Jason-1, Jason-2, and Envisat) data. 
TABLE 2. Performance of the considered meteorological approaches and corresponding wave model results. The comparison is vs scatterometer (wind speed) and altimeter (significant wave height) data, respectively. Bias and RMSE units are $\mathrm{m} \mathrm{s}^{-1}$ and $\mathrm{m}$, respectively. Slope, $r$, and SI are nondimensional. See appendix $\mathrm{C}$ for the definition of the statistical parameters.

\begin{tabular}{|c|c|c|c|c|c|c|c|c|c|c|}
\hline & \multicolumn{5}{|c|}{ Wind } & \multicolumn{5}{|c|}{ Wave } \\
\hline & Bias & RMSE & Slope & $r$ & SI & Bias & RMSE & Slope & $r$ & SI \\
\hline $1 \mathrm{deg}$ & -0.35 & 1.54 & 0.92 & 0.79 & 0.45 & -0.25 & 0.39 & 0.82 & 0.84 & 0.37 \\
\hline $\mathrm{EC}$ & -0.37 & 1.39 & 0.94 & 0.85 & 0.37 & -0.18 & 0.32 & 0.85 & 0.88 & 0.30 \\
\hline WRF-FC & 0.25 & 1.70 & 1.04 & 0.76 & 0.45 & -0.06 & 0.32 & 0.94 & 0.82 & 0.30 \\
\hline WRF-AN & -0.25 & 1.26 & 0.95 & 0.88 & 0.30 & -0.10 & 0.30 & 0.94 & 0.86 & 0.28 \\
\hline $\mathrm{EC}+$ & -0.04 & 1.39 & 1.02 & 0.85 & 0.37 & -0.05 & 0.28 & 0.97 & 0.88 & 0.27 \\
\hline
\end{tabular}

respect to the wind and wave system coming from the SSE. The results of the model versus buoy data comparison are given in Fig. 6. There is generally good agreement with practically all the meteorological models. The scatter is reduced with respect to Fig. 5. This is true also for the wave height results. The related statistics are given in Table 3.

To gain a better perspective, it is worthwhile to analyze some specific cases. For this, we need some continuity in time. Figure 7 shows the wind speed time series and buoy and model data for three periods. The upper panel, covering about a 1-month period, provides a general view and suggests that all the models, at a different degree of approximation, follow the locally measured data. Superimposed on the synoptic time-scale variability is a more or less pronounced daily cycle, suggesting the expected presence of land-sea breezes. These are more evident in the last 3 days shown in the middle panel of Fig. 7 and most of all in the first and last parts of the lower panel. The middle panel shows the wind conditions at the buoy during the most severe event of the year. Figure 8 presents the corresponding wave heights.

If we judge the performance of the models from these two figures, we see that using one degree resolution (1deg) leads almost systematically to too low and, perhaps the main characteristic, rather smooth evolution. WRF-FC is slightly better, but with a tendency, particularly in the wind plot, to overshoot the oscillations of the field. This may not heavily affect the best-fit slope, but it drastically increases the root-mean-square (rms) error and the scatter index (SI). Though EC gives a better solution than 1deg and WRF-FC, its resolution $(25 \mathrm{~km})$ might fail in reproducing small-scale variability over time (but see comments in the next section). The best results are given by WRF-AN. The higher resolution of this model, both in space and time, helps in reproducing the small variations more precisely, and the assimilation brings the model into better agreement with the observations.

More detailed information is provided by Figs. $7 \mathrm{~b}$ and 8 b, spanning about 8 days in May 2009, when the highest significant values $\left(H_{s}>4 \mathrm{~m}\right)$ were recorded. In this case, given the well-defined general pattern of sustained wind (not shown), 1deg and EC provide reasonable results, close to those of WRF-AN. In contrast, WRF-FC is waving, moving to higher and lower values well off the recorded ones. In particular, it misses the peak of the storm.

A similar comment can be derived from Figs. $7 \mathrm{c}$ and $8 \mathrm{c}$, selected because they show the relevant role of the landsea breezes in certain periods of the year (mid-August in these figures). The daily cycle is evident notwithstanding a sustained background. As expected, with some smoothing, EC follows the local wave pattern. The $1 \mathrm{deg}$ does this to a more limited extent with a more marked underestimation. Poorer results are obtained from WRF-FC, particularly in the first part of the diagram, which drastically underestimates the significant wave height, showing hardly any evidence of a daily cycle. Much better are the results of WRF-AN, which manages to represent the local daily pattern with sufficient accuracy.

Not surprising is that our comparisons show that the higher resolution of WRF-AN together with its data assimilation scheme leads to the best results. Given this result, we now ask if it is possible to improve the results of a coarser model. We suggested above that approach $v$ introduces the possibility of uniformly increasing the wind speeds from EC to reach, on average, the correct wave heights. Trial and error led to increasing the EC surface wind speeds by $7 \%$ (accurate to within $2 \%$ ). The corresponding scatterplots versus the scatterometer and altimeter data are given in Fig. 9 and those with the buoy data are in Fig. 10. The statistics are presented in Tables 2 and 3. Not surprisingly, there is an almost perfect fit for the wave heights. Similarly good results (not shown), but with some variability, were obtained for the time series discussed in Figs. 7 and 8.

It is worth analyzing also the results for the mean period at the buoy. These turned out (see Table 4) quite different from those of significant wave heights. Basically all the model values were larger than the buoy data, with the largest differences with WRF-FC and EC+ (note the large bias and best-fit-slope values and the decreased values of all the scatter indices). 

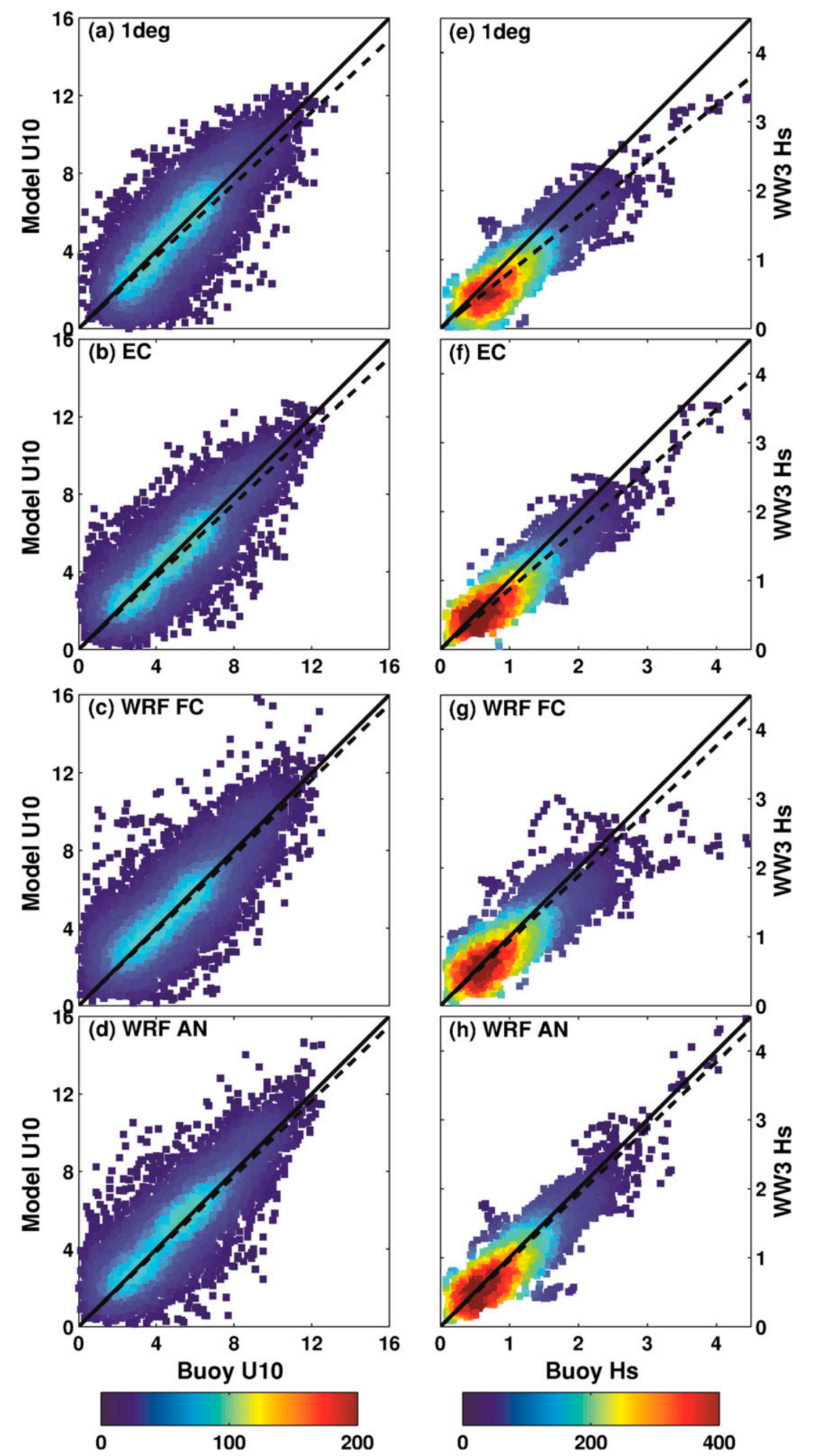

FIG. 6. As in Fig. 5, but for comparison with buoy data. See Fig. 1 for its position. 
TABLE 3. As in Table 2, but for the buoy-measured data. See Fig. 1 for its position.

\begin{tabular}{|c|c|c|c|c|c|c|c|c|c|c|}
\hline & \multicolumn{5}{|c|}{ Wind } & \multicolumn{5}{|c|}{ Wave } \\
\hline & Bias & RMSE & Slope & $r$ & SI & Bias & RMSE & Slope & $r$ & SI \\
\hline $1 \mathrm{deg}$ & 0.06 & 1.50 & 1.01 & 0.80 & 0.30 & -0.21 & 0.30 & 0.81 & 0.92 & 0.33 \\
\hline $\mathrm{EC}$ & 0.04 & 1.41 & 1.02 & 0.83 & 0.28 & -0.12 & 0.23 & 0.88 & 0.93 & 0.26 \\
\hline WRF-FC & 0.17 & 1.55 & 1.05 & 0.80 & 0.31 & -0.06 & 0.27 & 0.94 & 0.88 & 0.30 \\
\hline WRF-AN & -0.09 & 1.39 & 1.00 & 0.84 & 0.27 & -0.03 & 0.21 & 0.96 & 0.95 & 0.23 \\
\hline $\mathrm{EC}+$ & 0.39 & 1.58 & 1.09 & 0.83 & 0.30 & -0.01 & 0.20 & 0.99 & 0.93 & 0.23 \\
\hline
\end{tabular}

With the analysis of the temporal behavior of the models at the buoy position, it is also worthwhile to analyze different scenarios to understand the performance of the models under various situations.

\section{b. NNW winds covering the entire basin}

In this section, we describe the performance of the five atmospheric approaches in simulating winds and waves when the Red Sea is under the influence of only the NNW wind. This can be considered the easiest situation, with a distributed wind blowing in the same longitudinal direction along the whole basin. Indeed, a repeated comparison of the five corresponding fields (not shown) reveals strong similarity in the overall structure. However, differences are present in the actual values of wind speed and significant wave height. The statistics, versus scatterometer and altimeter data, are provided in Table 5. In contrast with the previous general results, the best ones (for bias and best-fit slope) come from WRF-FC for this scenario. Waves from the $\mathrm{EC}+$ approach are in excess, with the remaining models underestimating wave height at different levels. The best-fit slopes for wind and waves are generally consistent, with the wave height slopes more different from unity than those of the wind. A slight contradiction appears for WRF-AN with an excess for wind (slope $=1.03$ ) and an underestimation for wave height (0.96). A direct analysis is not possible because scatterometer and altimeters pass at different times. We consider this to be part of the general problem of a relatively limited amount of
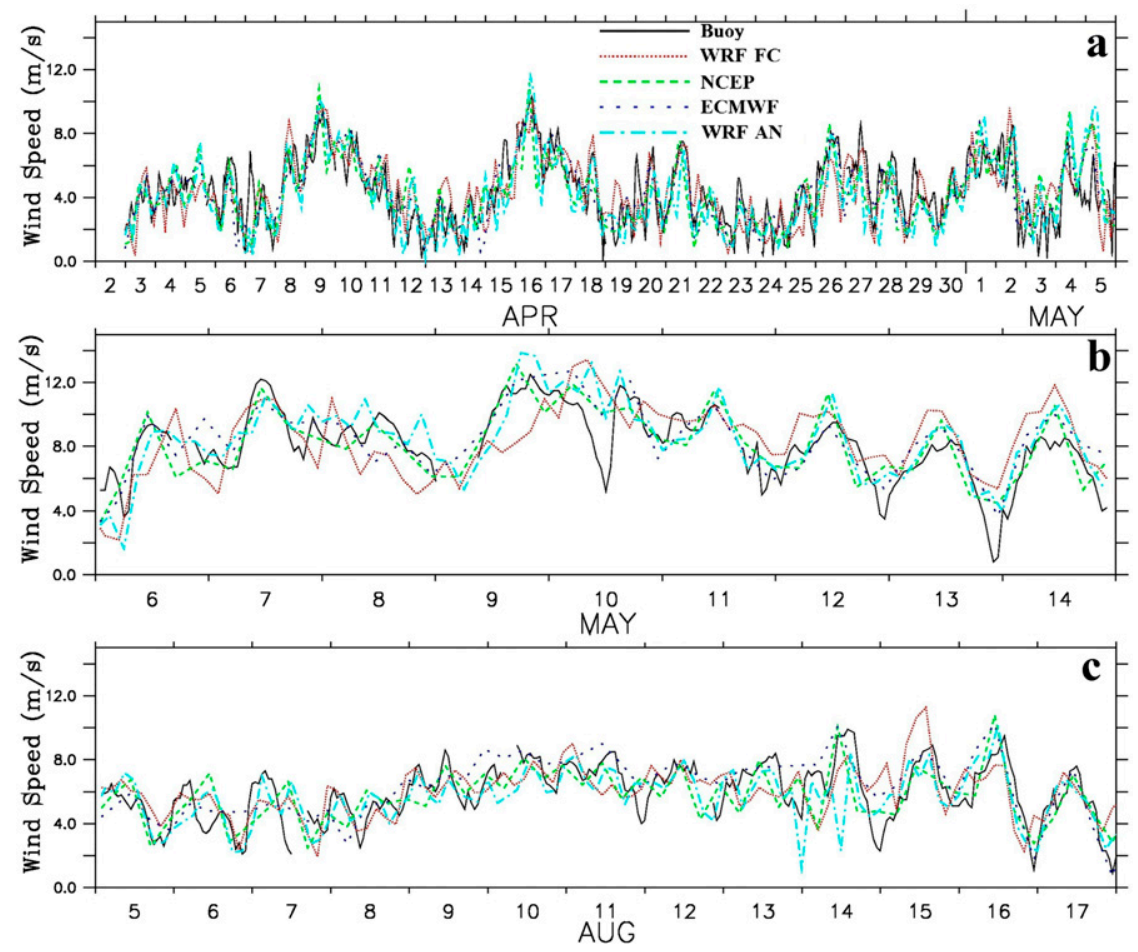

FIG. 7. Three cases of comparison between the measured wind speed time series at the buoy position (see Fig. 1) and the corresponding model values obtained with 1deg, EC, WRF-FC, and WRF-AN. (a) A general case, (b) the most severe storm recorded in the $2 \mathrm{yr}$ the buoy was deployed, and (c) typical daily breezes superimposed to a NNW wind. 

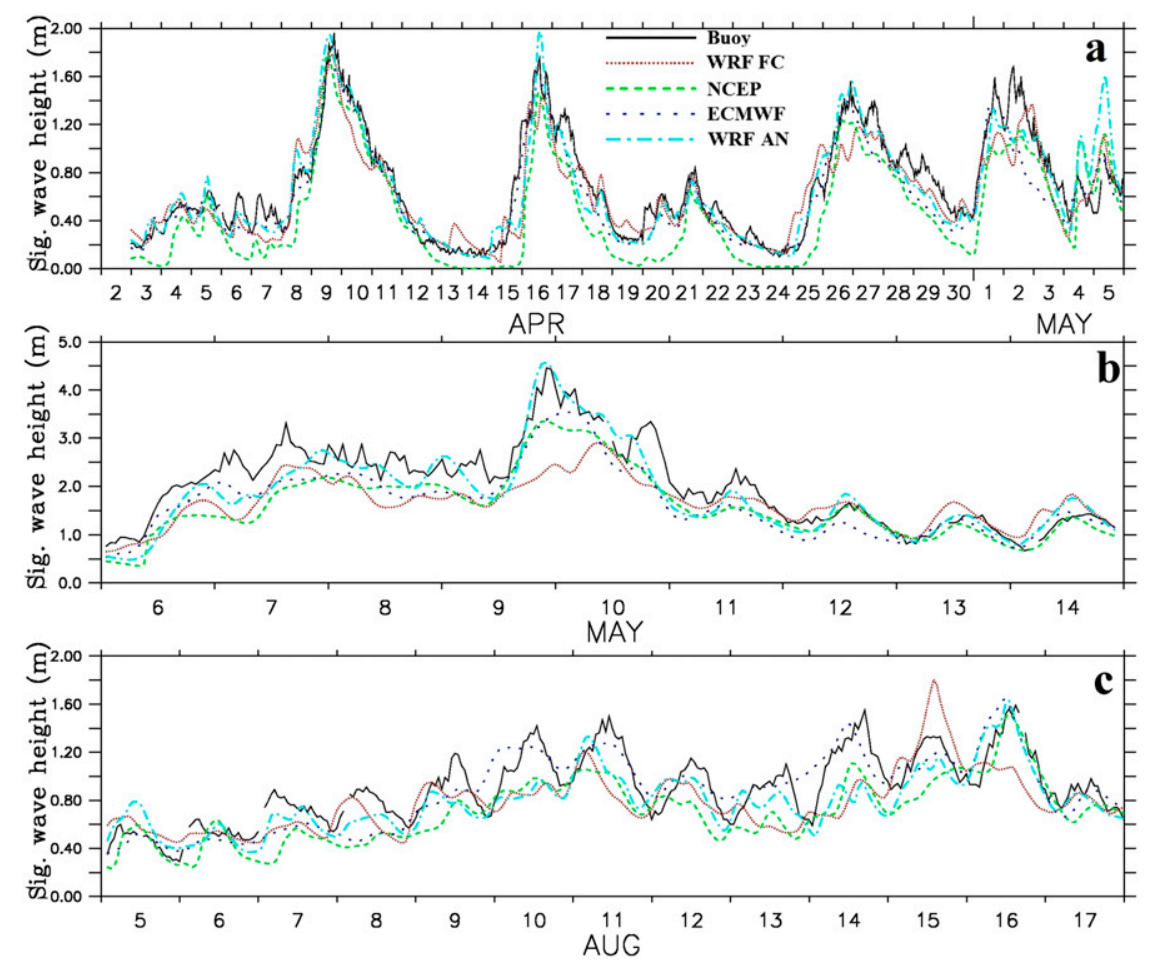

FIG. 8. As in Fig. 7, but for the significant wave height.

measured data (for NNW wind, 63 ASCAT passes and 87 altimeter passes). We therefore observe the more limited reliability of the statistical results when we look at the specific situations.

\section{c. Tokar Gap events}

The general Tokar Gap situation is shown in Figs. $2 b$ and 3a,c. Figure 11a provides a detailed view of the modeled wave field during a strong event. We are interested in intense cases (strong Tokar Gap winds), when a transversal spreading jet, and its derived waves, are superimposed on, and interact with, the SSE-flowing general field.

The mean directions seen in Fig. 11a are misleading in that they hide the more complex situation due to the superposition of two different wave systems. This is
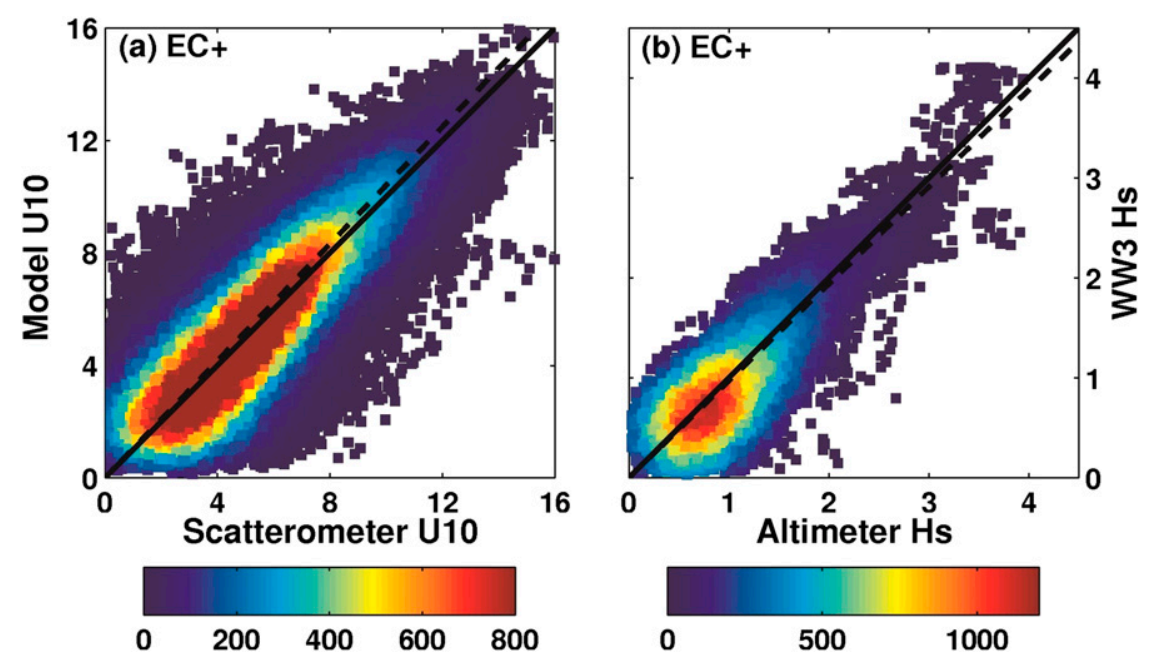

FIG. 9. Best fits of the enhanced (+7\%) EC+ wind speeds and derived wave heights vs scatterometer and altimeter data, respectively. 

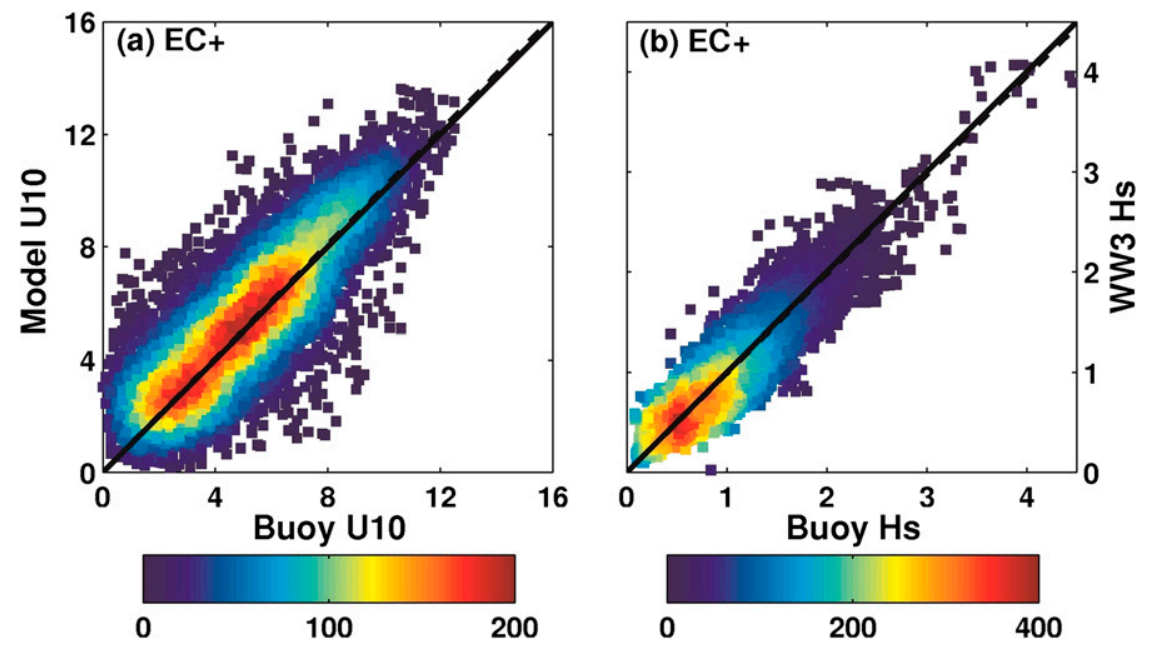

FIG. 10. As in Fig. 9, but for buoy data. See Fig. 1 for its position.

clearly shown in Fig. 12b. The one-dimensional (1D) spectrum shows the local wind sea superimposed on a small swell. The overall situation is well represented in the two-dimensional (2D) spectrum (lower panel). We see clearly the low-frequency swell plus the rather spread-out wind sea consequent to the spreading of the wind exiting the gap.

We have selected all the cases of Tokar Gap wind (10 of them) when (i) scatterometer and altimeter data are available and when (ii) the maximum modeled wind speed in front of the gap was higher than $7 \mathrm{~m} \mathrm{~s}^{-1}$. The statistics for the five different meteorological approaches are given in Table 6 . The best results (again for bias and best-fit slope) are provided by $\mathrm{EC}+$. The low correlation values compared to previous corresponding statistics and the much increased scatter indices demonstrate the limitations in modeling Tokar Gap winds.

The timely pass of the Jason altimeter tracked in Fig. 11a allows (Fig. 11b) a direct $H_{s}$ comparison with the various model results, here shown for WRF-AN, $\mathrm{EC}$, and $\mathrm{EC}+$. Apart from the point-by-point variability of the $H_{s}$ altimeter values, the three models reproduce the general $H_{s}$ profile, with only a slight underestimate on the left side of the jet, where the locally generated waves move almost against the incoming swell.

\section{d. Easterly jets}

The typical wind and wave patterns are shown in Figs. $3 \mathrm{~b}$ and $3 \mathrm{~d}$. Strong easterly winds blow from various gaps in the Arabian mountains (see Fig. 1) generating wind sea across the basin. Being mainly related to the overall synoptic situation, this pattern is relatively easy to model, with the resolution in principle crucial for properly representing the jets. The typical $1 \mathrm{D}$ and $2 \mathrm{D}$ spectra are shown in Fig. 12c.
We managed to find 11 cases of easterly jets during 2009 for which we had also scatterometer and altimeter data. The statistics for model results are given in Table 7. Within the limits of the limited sampling, in general, the high-resolution models have the most favorable best-fit slopes (all under unity, with underestimated model values), with consistency between the wind and wave results. The exception is $1 \mathrm{deg}$, with a relatively high wind slope, but a very low wave slope. The best results are provided by $\mathrm{EC}+$.

\section{e. Opposing wave systems}

There are no altimeter observations that document the convergence of opposing systems; no attempt has been made to compute the related statistics. However, it is interesting to analyze this unique situation in some detail. We focus our attention on the case depicted in Fig. 2c, with the two opposite winds, each covering half of the Red Sea along its axis direction. Each wind generates its own wind-wave system. We want to see how the wave conditions vary in the central part of the basin (at least according to model results). The convergence area is located in front of the Tokar Gap (see Figs. 1, 2c) through which the converging surface winds tend to escape. The typical 1D and 2D spectra are shown in Fig. 12a (upper and lower panels). From a more complete perspective, Fig. 13

TABLE 4. As in Table 3, but for wave mean period.

\begin{tabular}{lccccc}
\hline & Bias & RMSE & Slope & \multicolumn{1}{c}{ SI } \\
\hline 1deg & 0.13 & 0.55 & 1.04 & 0.74 & 0.13 \\
EC & 0.26 & 0.58 & 1.07 & 0.8 & 0.13 \\
WRF-FC & 0.53 & 0.77 & 1.16 & 0.73 & 0.18 \\
WRF-AN & 0.17 & 0.56 & 1.06 & 0.81 & 0.13 \\
EC+ & 0.57 & 0.78 & 1.15 & 0.8 & 0.18 \\
\hline
\end{tabular}


TABLE 5. As in Table 2, but for the NNW winds: 63 scatterometer and 87 altimeter passes.

\begin{tabular}{|c|c|c|c|c|c|c|c|c|c|c|}
\hline & \multicolumn{5}{|c|}{ Wind } & \multicolumn{5}{|c|}{ Wave } \\
\hline & Bias & RMSE & Slope & $\mathrm{r}$ & SI & Bias & RMSE & Slope & $r$ & SI \\
\hline $1 \mathrm{deg}$ & -0.18 & 1.33 & 0.95 & 0.85 & 0.34 & -0.17 & 0.34 & 0.88 & 0.86 & 0.35 \\
\hline $\mathrm{EC}$ & -0.15 & 1.18 & 0.97 & 0.89 & 0.27 & -0.06 & 0.26 & 0.93 & 0.89 & 0.27 \\
\hline WRF-FC & -0.01 & 1.50 & 1.00 & 0.77 & 0.39 & 0.02 & 0.31 & 1.00 & 0.76 & 0.32 \\
\hline WRF-AN & 0.17 & 1.49 & 1.03 & 0.83 & 0.33 & -0.08 & 0.31 & 0.96 & 0.86 & 0.30 \\
\hline $\mathrm{EC}+$ & 0.20 & 1.23 & 1.04 & 0.89 & 0.29 & 0.06 & 0.28 & 1.06 & 0.90 & 0.28 \\
\hline
\end{tabular}

provides the 2D spectra (flow direction) along a series of points, from $\mathrm{N}$ to $\mathrm{S}$, shown in Figs. 14a and 14b. Figures $14 \mathrm{c}$ and $14 \mathrm{~d}$ show, respectively, the peak and total energy (variance) of the two opposing systems. Over all the points, two opposing wave systems are present. Starting with the most northerly point (to avoid confusion we use here flow direction for both wind and waves), we have a dominant southeast (SE)-propagating wind sea and a much lower northwest (NW)-propagating swell. As we move southward, both the SE and NW wave systems strengthen, although for different reasons. The SE wind sea increases along its fetch, while the NW swell goes back along its dissipation path. In particular, moving southward, we see the growing extent of the frequency range from the SE-blowing wind. The two systems become comparable in the wind convergence area, between $20^{\circ}$ and $21^{\circ} \mathrm{N}$, close to the Tokar Gap. South of this area, the NW-going waves become the dominant system, whereas the former SE wind sea, now moving against the local wind, mirroring the NW area pattern described above, progressively reduces its level to a low energy swell. The NW-blowing wind is at its maximum just north of the Bab el Mandeb strait because of the strong monsoon flow in this area.

\section{Discussion}

In the previous section, we reported results obtained by various meteorological and wave models, with only some brief comments about their performance. In this section, we analyze the performance of the models and try to explain the reasons for the various (relative) failures or successes.

\section{a. The general wind pattern}

A narrow, 2250-km-long basin, bordered on both sides by a relevant orography, is not in itself a simple problem. The major winds are aligned with the main axis of the basin, but this apparently simple pattern is strongly perturbed by the lateral strong jets, a frequent feature in case of the Tokar Gap. It is intuitive that the coarse resolution, in space and in time, of the large-scale models does not suit the specificity of the local setting of the Red Sea. Nevertheless, we were surprised by the
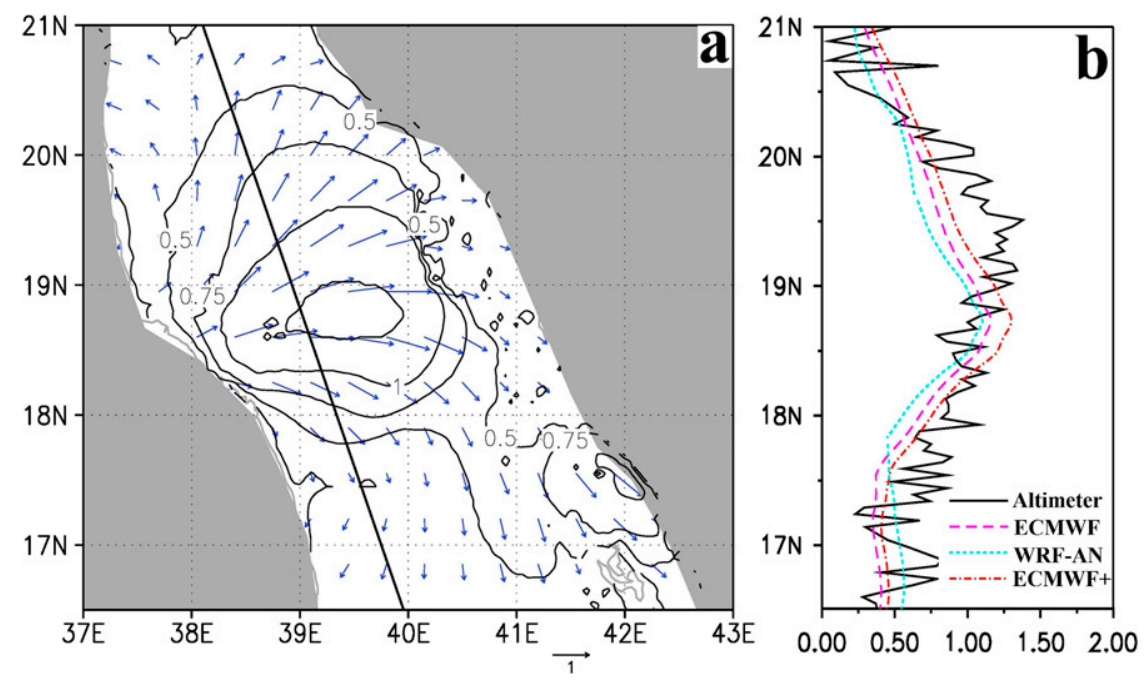

FIG. 11. Altimeter pass during a Tokar Gap event. (a) Wave field with EC wind. Isolines at 0.25-m interval. (b) Comparison between the altimeter significant wave heights and the corresponding model data from WRF-AN, regular, and EC+ wind speeds. 

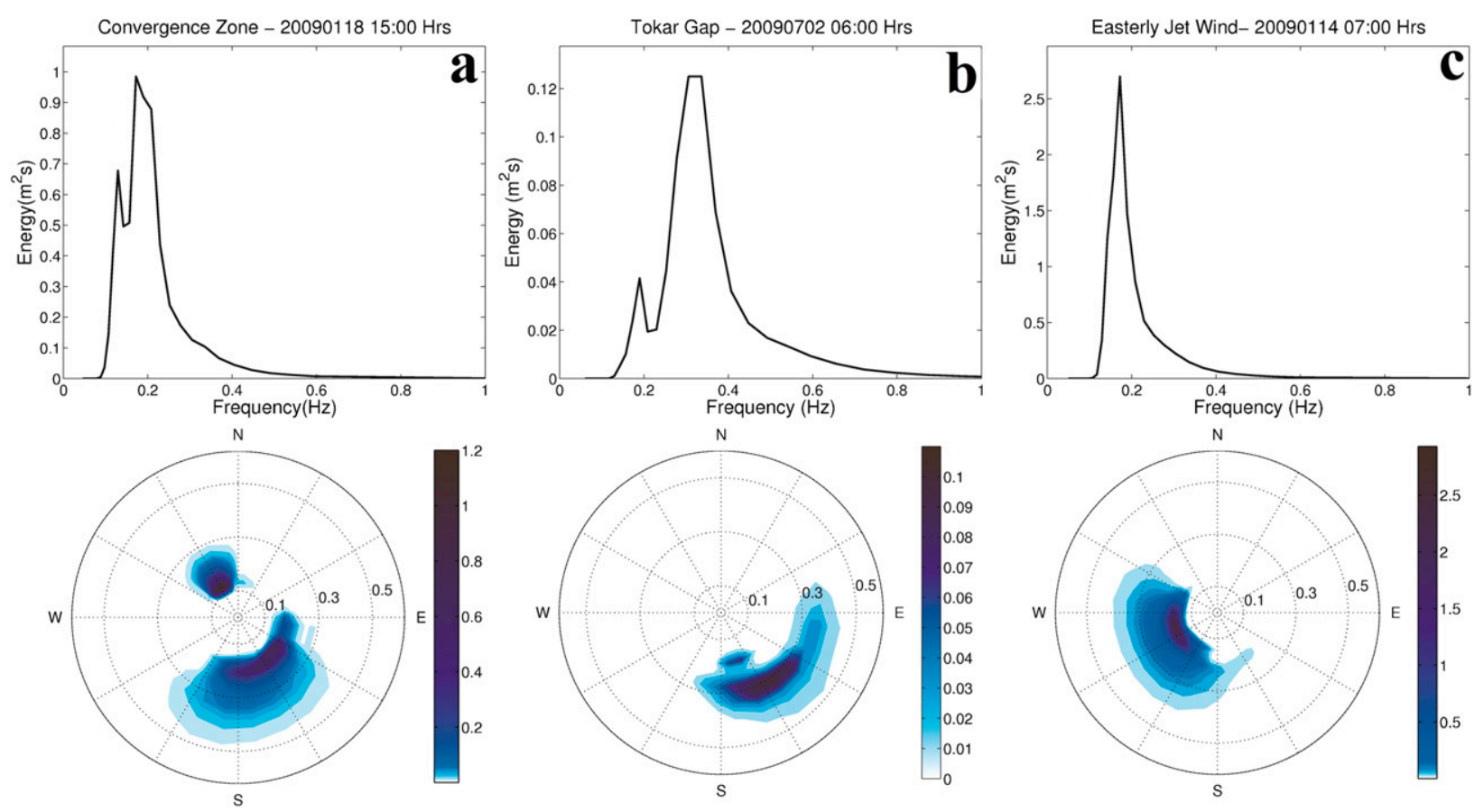

FIG. 12. 1D and 2D spectra in the center of the Red Sea for the three situations shown respectively in Figs. 2c, 3c (or Fig. 11a), and 3d.

relatively good performance of the EC model. However, the main, and most unusual, feature of the local wind fields is the convergence zone, where the two opposing winds, from the NW and SE, meet. The detailed dynamics in the convergence area, for instance the precise position of the area, is extremely sensitive to small variations of the overall pattern. In turn, the dynamics has relevant consequences on the derived wave fields, introducing variability in the models' results as reflected in, among other things, the large scatter of the model data in comparison with satellite and buoy data.

\section{b. Improving global meteorological model results}

We have identified the main reason for the reasonable performance of the ECMWF meteorological model, as judged by the derived wave heights, as its capability to frame the general situation well and to provide the correct isobar and wind patterns. Indeed, a simple uniform and constant increase of about $7 \%$ of the wind speed has been sufficient to lead to an almost optimal fit with the wave-measured data. However, similar previous results by Cavaleri and Bertotti $(1997,2004)$ suggest that the enhancement factor could be dependent on the fetch and therefore may differ, either lower and higher, respectively, for the along- and across-axis flows. Indeed, this would be consistent with the excess reported in section $5 \mathrm{~b}$ for $\mathrm{EC}+$. We considered this possibility, but the limited and sparse amount of available measured data suggested that a meaningful and reliable result with the required accuracy could not be reached. The use of the WRF-AN winds as a reference ground was suggested to us for a more refined tuning of the EC wind speeds. ${ }^{1}$ This will require a nonstraightforward analysis because of the large scatter we expect from such a comparison, certainly larger than what is already indicated by the various scatter indices for wind speed.

We also considered enhancing the $1 \mathrm{deg}$ wind data. However, the results suggested that the resolution of the available data $\left(1^{\circ}\right)$ was too coarse to follow this line of action. An enhancement would possibly lead to an overall unitary best-fit line for wave height, but with an even larger scatter, for both the wind and wave data. We therefore chose not to follow this possibility.

In the previous section, we have repetitively commented on the lack, contrary to the recorded data, of short-term variability in the model results (both wind and waves). A model, and more so if at large scale, has certainly a tendency to smooth the natural fields. However, it is correct to point out that some of the variability seen in the various plots of the recorded data (see Figs. 7, 8 , and 11 b) is what can be reported as "noise," at least in a statistical sense, and is because of errors in the instrument. Note also that increasing the model resolution does not necessarily improve (decrease) the scatter because a high-resolution meteorological model, with

\footnotetext{
${ }^{1}$ We thank an anonymous reviewer for this suggestion.
} 
TABLE 6. As in Table 2, but for the Tokar Gap events. Ten cases have been considered.

\begin{tabular}{|c|c|c|c|c|c|c|c|c|c|c|}
\hline & \multicolumn{5}{|c|}{ Wind } & \multicolumn{5}{|c|}{ Wave } \\
\hline & Bias & RMSE & Slope & $r$ & SI & Bias & RMSE & Slope & $r$ & SI \\
\hline $1 \mathrm{deg}$ & -0.30 & 1.67 & 0.92 & 0.72 & 0.46 & -0.19 & 0.35 & 0.79 & 0.58 & 0.47 \\
\hline $\mathrm{EC}$ & -0.24 & 1.27 & 0.94 & 0.86 & 0.33 & -0.06 & 0.26 & 0.9 & 0.61 & 0.35 \\
\hline WRF-FC & 0.30 & 2.09 & 1.08 & 0.66 & 0.52 & 0.11 & 0.39 & 1.19 & 0.47 & 0.51 \\
\hline WRF-AN & 0.51 & 1.55 & 1.02 & 0.79 & 0.35 & -0.09 & 0.26 & 0.9 & 0.63 & 0.33 \\
\hline $\mathrm{EC}+$ & 0.09 & 1.27 & 1.01 & 0.86 & 0.33 & 0.04 & 0.26 & 1.02 & 0.62 & 0.35 \\
\hline
\end{tabular}

a rapidly changing variable (e.g., wind speed) can be physically meaningful in a statistical sense, but not deterministic for what concerns the small scales, hence rapid oscillations.

\section{c. High-resolution local meteorological modeling}

Having recognized the limits of the large-scale models, it was natural to approach the problem using a highresolution local model. Our first attempt was to use WRF in the forecast mode (WRF-FC). Given the direct availability of its data for possible operational purposes, we used $1 \mathrm{deg}$ as a boundary forcing model for the initial analyses and the subsequent boundary conditions. The results were disappointing in that the WRF-FC wind results often performed more poorly than the $1^{\circ} \mathrm{NCEP}$ model. WRF-FC demonstrated a clear tendency to overreact, with the wind modulus often oscillating around the 1deg data. We verified this observation with buoy data, which was our only source of hourly data and the result was not completely surprising. Previous experience in other areas [see, among others, Bertotti et al. (2014) for extensive tests in the western Mediterranean Sea] has shown that limited-area models are only as good as the information provided by the boundaryforcing models. We think that a $1^{\circ}$ resolution is too coarse to provide suitable input and boundary information for basins like the Red Sea. We do stress that with NCEP and ECMWF we are dealing with analysis fields, whereas with WRF-FC we are using the +12 - to +30 -h forecasts. However, within this narrow forecast range, models are not expected, at least within the general indications we are looking for in this paper, to deteriorate appreciably [see for instance the ECMWF statistics by Richardson et al. (2013)]. The solution was to use high-resolution local analysis, WRF-AN. In so doing, we took advantage of the available data and took into account all the features of the Red Sea basin (the details are presented in appendix B). Indeed, this improved substantially the quality of the wind and wave data. This was true not only for the best-fit slope versus measured data, but, perhaps more significantly, for the scatter. The results shown in Figs. 5 and 6 and presented in Tables 2 and 3 are significant.

Compared with that of high-resolution WRF-AN, the performance of EC+ depends on the general meteorological situation. If the smallest details of the field are important, like in the case of the small but strong jets from the eastern side, then WRF-AN should provide a more realistic picture (narrower jets) of the situation. If, as in the case of the major storm on 9 May 2009 (see Figs. 7 and 8), the pattern follows a large scale, then both the NCEP and ECMWF global models perform competitively.

\section{d. Sea breezes}

A special issue is sea breezes, whose daily cycle is not properly captured by any model. Of course, we have only one data collection point from which to judge the results, that is, the buoy that was moored about $50 \mathrm{~km}$ off the coast. The clear presence in Fig. 7 of "breeze waves" superimposed to the background field indicates that the breeze-affected area may extend well beyond the buoy. Indeed, assuming that the background field is parallel to the coast, a simple estimate of the breeze-generated wave energy at the buoy suggests that the breeze fields may extend at least $100 \mathrm{~km}$ from the coast. This implies

TABLE 7. As in Table 2, but for easterly jets. Eleven cases have been considered.

\begin{tabular}{|c|c|c|c|c|c|c|c|c|c|c|}
\hline & \multicolumn{5}{|c|}{ Wind } & \multicolumn{5}{|c|}{ Wave } \\
\hline & Bias & RMSE & Slope & $r$ & SI & Bias & RMSE & Slope & $r$ & SI \\
\hline $1 \mathrm{deg}$ & -0.30 & 1.29 & 0.95 & 0.86 & 0.25 & -0.17 & 0.34 & 0.81 & 0.65 & 0.37 \\
\hline $\mathrm{EC}$ & -0.66 & 1.16 & 0.91 & 0.93 & 0.20 & -0.07 & 0.26 & 0.89 & 0.76 & 0.29 \\
\hline WRF-FC & -0.24 & 1.59 & 0.96 & 0.79 & 0.39 & -0.01 & 0.29 & 0.97 & 0.66 & 0.32 \\
\hline WRF-AN & -0.35 & 1.70 & 0.95 & 0.76 & 0.43 & -0.08 & 0.25 & 0.97 & 0.76 & 0.25 \\
\hline $\mathrm{EC}+$ & -0.24 & 1.03 & 0.98 & 0.93 & 0.16 & 0.05 & 0.25 & 1.02 & 0.77 & 0.27 \\
\hline
\end{tabular}


Lon:35.50,Lat:26.00 Lon:36.00,Lat:25.00 Lon:36.25,Lat:24.50
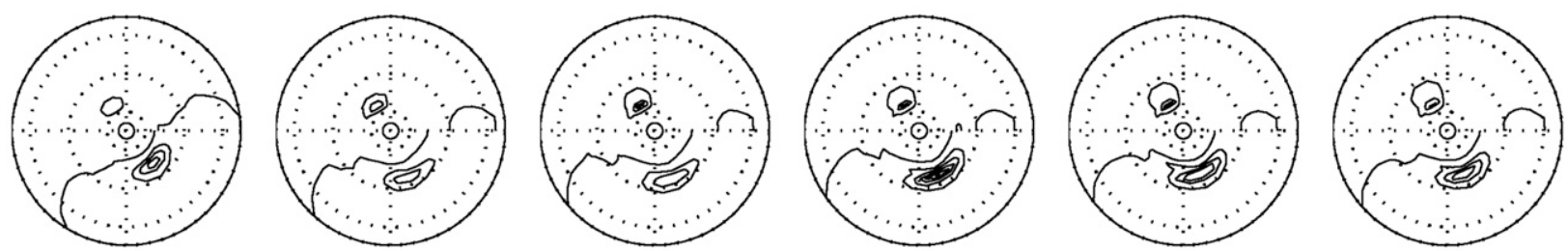

Lon:37.50,Lat:22.50
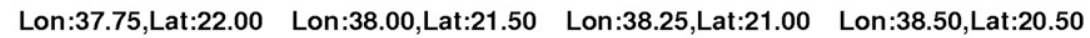

Lon: 38.75 , Lat: 20.00
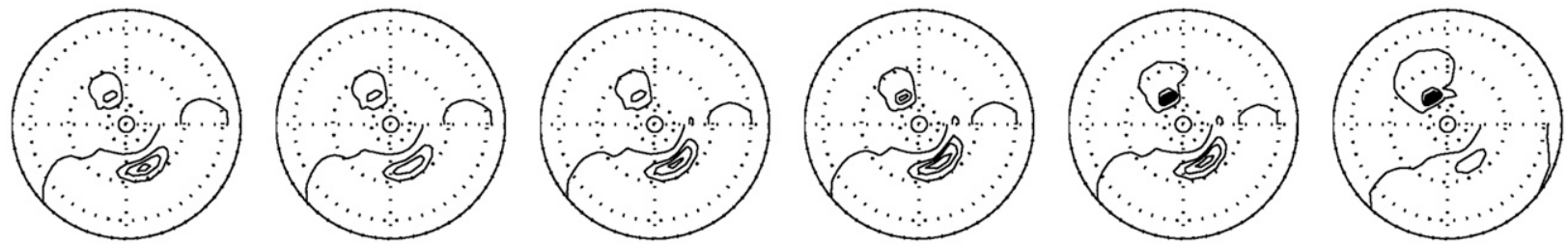

Lon:39.00,Lat: 19.50
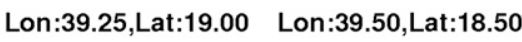

Lon: 40.00 ,Lat: 18.00

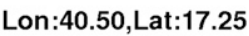

Lon:41.00,Lat: 16.50
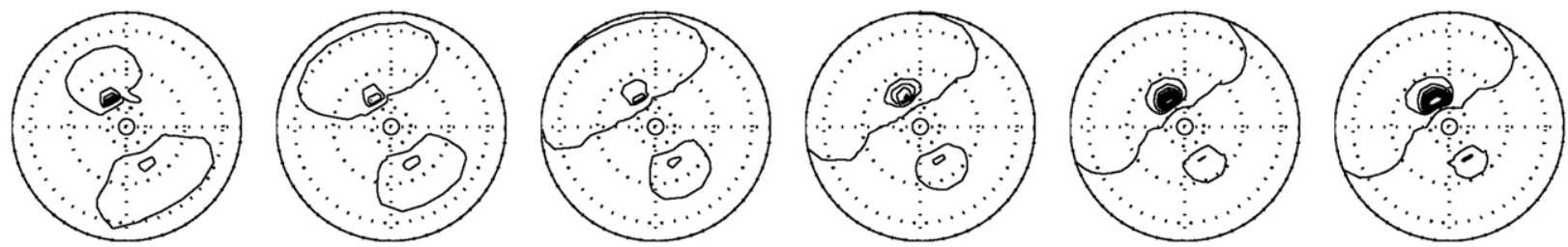

FIG. 13. 2D wave model spectra (EC+ wind speeds) along the line NNW-SSE across the convergence zone on 7 Jan 2009. See Fig. 14 for the distribution of points.

that most of the basin, if not the whole of it, is affected by the daily breezes. This is consistent with reports in the literature (see, e.g., Steele et al. 2012).

\section{e. Wave modeling}

Wind waves mirror the standard problems in wind modeling. We have pointed out that, because of insufficient resolution, the EC easterly jets are wider and hence less realistic than those modeled by WRF-AN. This implies that the peak wind speeds modeled by EC are lower. Because wind waves are an integrated effect of the driving wind fields, the $H_{s}$ differences are not so evident. However, differences exist in the directional spread of the 2D spectra of the waves, the diverging narrower jets leading to wider distributions than the more uniform along-the-coast $\mathrm{EC}$ winds.

In Tables 5 and 7, we see that EC+ results have exceeded the available measurements by $6 \%$ for the NNW winds and $2 \%$ for the easterly jets. This is consistent with the observation by Cavaleri and Bertotti (2004) that the model's underestimate of the surface wind speeds decreases as the fetch increases. Again this would suggest a fetch-dependent (and direction dependent) calibration of wind speed, but we feel we do not have enough data to follow with a sufficient accuracy this conclusion. Indeed, once we consider the number of cases available for each specific situation, we realize that the conclusions we have derived can only be considered as valuable approximations. This is also how we interpret what in a couple of cases can be referred to as apparent contradictions between wind and corresponding wave results.

A more serious issue is raised from the results presented in Table 3 ( $U_{10}$ and $H_{s}$ at the buoy) and Table 4 (wave mean period). Clearly, the model mean periods are larger than expected from the $H_{S}$ results. We believe this comes from the sea breeze. In section $6 \mathrm{~d}$, we pointed out that all the meteorological models, and more so the large-scale ones, underestimate the sea breeze wind speed and its spatial extent. This leads to an underestimate of the related higher-frequency energy in the wave spectrum. This is clearly shown in Fig. 15, which presents a comparison between the $2 \mathrm{D}$ spectra from the models and as measured at the buoy. Apart from the directional spread of the buoy spectrum consequent to the analysis method (Steele et al. 1992) used for the NDBC buoys, the lack of high-frequency energy in the model spectra is evident. The consequence, limited for 

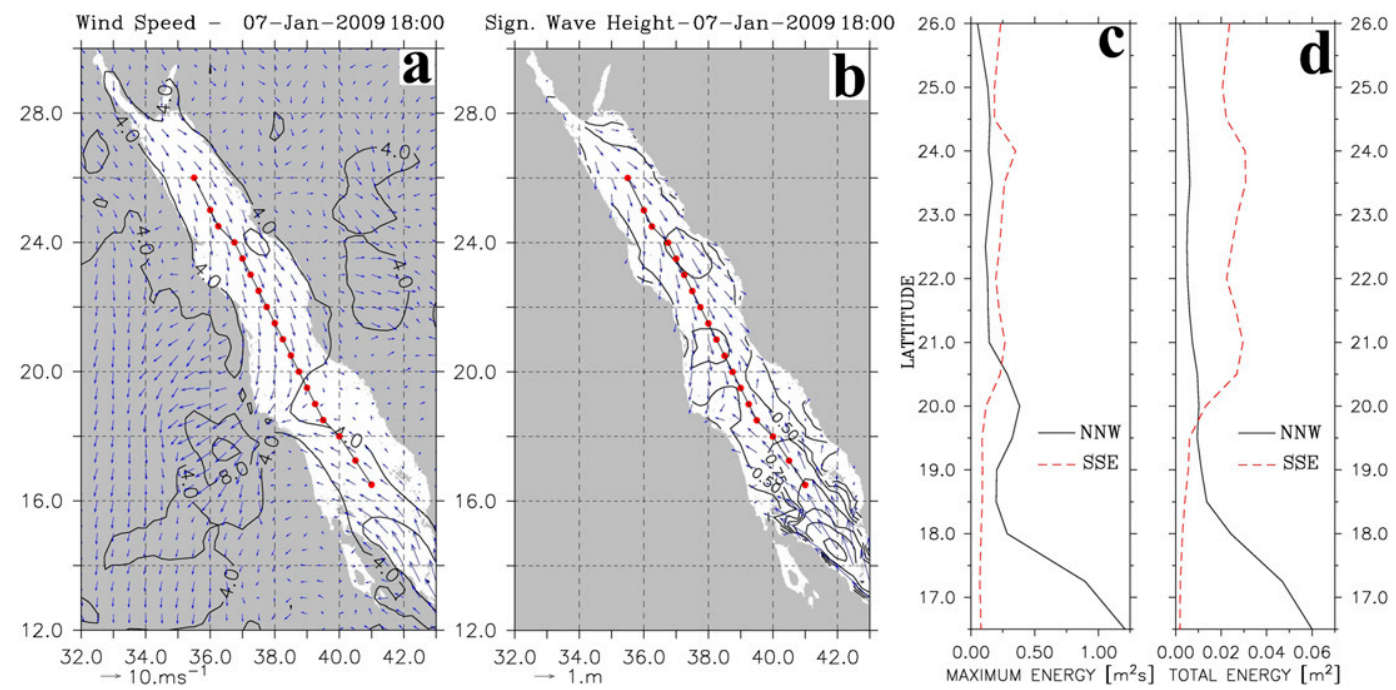

FIG. 14. (a) Wind speed and (b) significant wave height fields during the convergence event of 7 Jan 2009. (c) 2D peak spectral density and (d) total energy (variance) of the two wave converging systems along the line shown in (a) and (b). The EC + wind speed case is considered. NNW and SSE are flow directions.

what wave height is concerned, is an overestimate of the model mean period, as shown in Table 4.

A general point we did not yet mention is the accuracy of the wave data from the buoy. Because there were not enough, if any, altimeter passes close enough to the buoy for a triple colocation analysis, we could not explore the accuracy of the buoy's wave height data. Apart from the report by Ralston et al. (2013), we rely on the general consistency between the model results obtained from a comparison with both altimeter and buoy data. Moreover, we believe that the general conclusions we have drawn about wind and wave modeling in the Red Sea would stand despite potential limited errors in the buoy wave heights.

\section{f. Wave model source functions}

Having discussed in the previous subsections windrelated problems, we now focus on the physics of the wave model. Indeed, the unusual conditions in the Red Sea give rise to some obvious questions.

First, we consider the Tokar Gap results. There (see the examples in Figs. 2b and 11a), the outgoing jet impinges at cross angle, but with a large directional spread, on the well-developed SE-flowing wave system. This is a difficult scenario to capture in a wave model [and one of the tests in the classical Sea Wave Modeling Project (SWAMP) study (Allender 1985)]. However, it is not unusual because it is similar to what may happen behind a rapidly moving cold meteorological front. The interactions and the ensuing dissipation depend on the intensity of the lighter general SE-flowing wind and hence on the stage of development when the SE-propagating waves come across the Tokar Gap wind area. If the SE wind is strong enough, the related waves would be well developed, and the interaction with the across wind and the related young waves would be limited. In this case, a separation in the model of the white-capping dissipation between the swell and wind sea, following Bidlot et al. (2007) and Ardhuin et al. (2010), is expected to help. The situation is more complicated when, because of a lighter SE wind, the related waves are characterized by a frequency closer to the one of the Tokar Gap waves. Indeed, in Fig. 11, we see a clear underestimate by the models on the left side of the jet, that is, where the locally generated waves move almost opposite to the incoming NNW ones.

Following this line of thinking, we are more concerned with the convergence of the opposing winds in the winter months (Figs. 2c and 14b) when the situation is absolutely unusual, and, as far as we know, not sufficiently discussed in the literature. Superimposed wind sea and swell moving in opposite directions can be relatively common in oceans. Indeed Garcia-Nava et al. (2009) studied fetch-limited generation by the Tihuano wind superimposed on a long period swell moving toward the coast. The Red Sea case is different. We have two opposing wind seas of similar amplitude and frequency, each under the action of its own wind until the convergence zone. Such a situation has not been considered in formulating and tuning the various dissipation source functions in the models [see the extensive discussion by Babanin (2011)].

By analyzing in detail how the wave conditions change from point to point in Fig. 13 (see Fig. 14 for the 

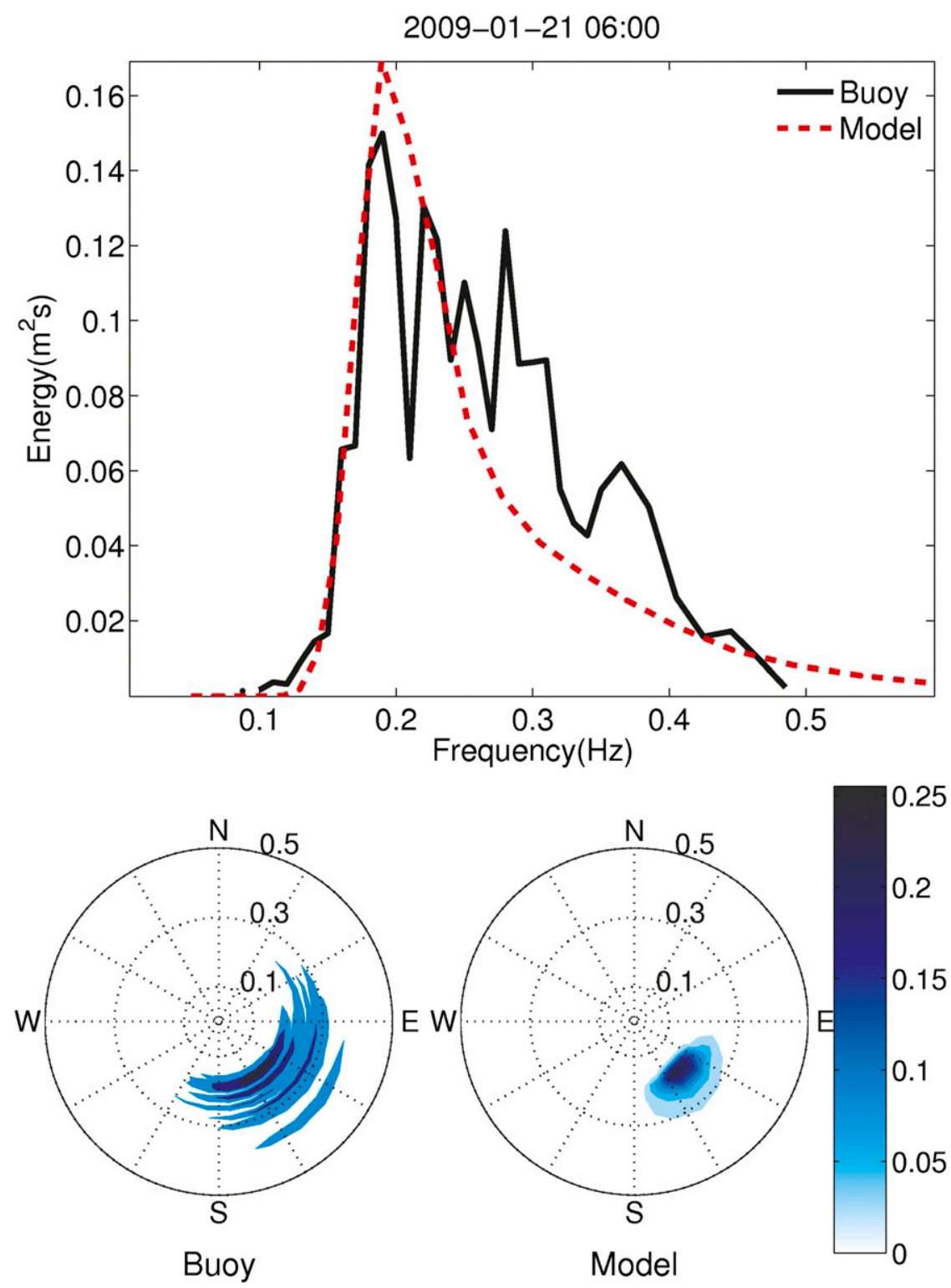

FIG. 15. 1D and 2D wave spectra from model and measured at the buoy during an active sea breeze event. See Fig. 1 for its position.

distribution of the spectra locations), we see that in the two extreme areas there is basically a swell moving against the local wind sea. Consequently, in these areas, like for the Tihuano wind observed by Garcia Nava et al. (2009), the dissipation can be reasonably represented in the wave model. Our main concern is for the central area where the two opposing systems have similar frequencies. In a way, we could imagine this as an area of irregular standing waves, and a suitable representation of the associated dissipation in the formulations of the present spectral wave models seems not to be available. Nevertheless, the models seem to do a reasonable job overall, at least for the significant wave height. There was no ideal altimeter pass like the one in Fig. 11 during an intense "convergence" event. However, there were several passes across the axis of the basin. In general, given the available data, the performance of the wave models in the convergence area was similar to the other more standard situations. We believe that this is because of the relatively limited extent of the real "standing waves" area and therefore there is a limited overall effect on the basin's wave field and overall statistics. No doubt, the condition deserves further attention, along with the formulation of the nonlinear wave-wave interactions, whose standard discrete interaction approximation (DIA) approach in operational applications 
seems not to capture the unique scenario in the Red Sea. As discussed above, a more precise statement will require a more dedicated analysis.

Clearly, the unique conditions of the Red Sea suggest that it is a natural laboratory to test specific aspects of local and large-scale meteorological and oceanographic models. In the example of the Tokar Gap, the local wave and circulation conditions strongly depend on the geometry of the jet and on how it interacts with the axial flow along the basin. The cross sea and partially opposing active generation of a wave system from the NW (see Fig. 12) deserves further attention.

In addition, more work needs to be done to understand the convergence zone and the implications of the various source functions in those areas. For a proper study, first we need to make sure that the meteorological modeling places the convergence at the correct position.

Further, an accurate modeling of the circulation pattern in the Red Sea, besides being valuable in itself, could quantify its role in wave modeling, partially where, as the convergence zone, the conditions may be very sensitive to also limited variations of the background information.

Acknowledgments. The research reported in this paper was supported by funding from King Abdullah University of Science and Technology. We are grateful to Jean Bidlot and an anonymous reviewer for suggestions that led to improvements in the paper. We also thank Dr. J. Tom Ferrar from Woods Hole Oceanographic Institution (WHOI; Woods Hole, Massachusetts) and Dr. Yasser Abualnaja and Mr. Mohammedali Nellayaputhenpeedika from King Abdullah University of Science and Technology (KAUST; Thuwal, Saudi Arabia) for assistance with the buoy data. Luigi Cavaleri took part in this study as part of the EU-funded MyWave project, Theme (SPA.2011.5-03).

\section{APPENDIX A}

\section{The WRF Forecast Approach}

In the WRF-FC approach, the WRF model is configured with two domains of horizontal resolutions of 30 and $10 \mathrm{~km}$ with 35 vertical levels. The large parent domain at $30-\mathrm{km}$ resolution extends from $5^{\circ} \mathrm{S}$ to $39^{\circ} \mathrm{N}, 16^{\circ}$ to $64^{\circ} \mathrm{E}$ and the inner child domain at $10-\mathrm{km}$ resolution covers the Red Sea basin from $9^{\circ}$ to $30^{\circ} \mathrm{N}, 31^{\circ}$ to $47^{\circ} \mathrm{E}$. Model simulations for WRF-FC are done following a consecutive integration method with daily initialization at 1200 UTC for 36-h lead time and the first $12 \mathrm{~h}$ neglected for model spinup. This is similar to the approach followed in the studies by Lo et al. (2008), Jiang et al. (2009), and Ralston et al. (2013) using $1^{\circ} \times 1^{\circ}$ data obtained from NCEP. For accurate representation of land-sea contrast and improving wind forecasts over coastal regions, time-varying sea surface temperature (SST) from the Real-Time Global High-Resolution (RTG-HR) (Gemmill et al. 2007) with $1 / 12^{\circ}$ horizontal grid resolution is replaced with coarse-resolution lower SST boundary conditions obtained from NCEP data. The model physics include Yonsei University (Hong et al. 2006) nonlocal diffusion scheme for planetary boundary layer (PBL) processes, Kain-Fritsch (Kain and Fritsch 1993) for cumulus convection, WRF Single-Moment 3-Class (WSM3) for microphysical processes, Noah land surface scheme (Chen and Dudhia 2001) for surface processes, Rapid Radiation Transfer Model (RRTM) for longwave radiation (Mlawer et al. 1997), and the Dudhia (1989) scheme for shortwave radiation.

\section{APPENDIX B}

\section{The WRF Analysis Approach}

In the WRF-AN approach, WRF reanalysis is produced using the same configuration as WRF-FC but assimilating NCEP Atmospheric Data Project (ADP) observations using three-dimensional variational data assimilation (3DVAR) as part of the WRF data assimilation (WRFDA) system. This method is similar to the Arctic System Reanalysis (Bromwich et al. 2010) with the same resolutions of two domains used in the WRF-FC approach. The observations used for reanalysis include the conventional observations from surface stations (synop, metar, ships, and buoy), upper-air soundings (rawinsonde and pilot) and satellite observations from such wind vectors as the Quick Scatterometer (QSCAT), WindSat, and ASCAT scatterometers, and atmospheric motion vectors from geostationary satellites.

\section{APPENDIX C}

\section{Statistical Parameters Used for the Model-Measured Data Intercomparison}

The definitions of the statistical parameters used in the study are given below.

(i) Bias, mean of the difference between the model data $\left(M_{i}\right)$ and buoy observations $\left(B_{i}\right)$ :

$$
\operatorname{Bias}=\frac{1}{n} \sum_{i}\left(M_{i}-B_{i}\right) .
$$

(ii) The root-mean-square error: 


$$
\mathrm{RMSE}=\sqrt{\frac{\sum_{i}\left(M_{i}-B_{i}\right)^{2}}{n} .}
$$

(iii) Correlation coefficient:

$$
r=\frac{\sum_{i}\left(M_{i}-\bar{M}\right)\left(B_{i}-\bar{B}\right)}{\sqrt{\sum_{i}\left(B_{i}-\bar{B}\right)^{2}} \sqrt{\sum_{i}\left(M_{i}-\bar{M}\right)^{2}}},
$$

where $\bar{M}$ and $\bar{B}$ are the average values of model and buoy observations, respectively.

(iv) Scatter index:

$$
\mathrm{SI}=\frac{\mathrm{RMSE}}{\bar{B}}
$$

\section{REFERENCES}

Allender, J. H., and Coauthors, 1985: Sea Wave Modelling Project (SWAMP), An intercomparison study of wind wave prediction models. Part 1: Principal results and conclusions. Ocean Wave Modeling, Plenum, $256 \mathrm{pp}$.

Ardhuin, F., and Coauthors, 2010: Semiempirical dissipation source functions for ocean waves. Part I: Definition, calibration and validation. J. Phys. Oceanogr., 40, 1917-1941, doi:10.1175/ 2010JPO4324.1.

Babanin, A., 2011: Breaking and Dissipation of Ocean Surface Waves. Cambridge University Press, $463 \mathrm{pp}$.

Bentamy, A., D. C. Fillon, and C. Perigaud, 2008: Characterization of ASCAT measurements based on buoy and QuikSCAT wind vector observations. Ocean Sci., 4, 265-274, doi:10.5194/ os-4-265-2008.

Bertotti, L., P. Canestrelli, L. Cavaleri, F. Pastore, and L. Zampato, 2011: The Henetus wave forecast system in the Adriatic Sea. Nat. Hazards Earth Syst. Sci., 11, 2965-2979, doi:10.5194/ nhess-11-2965-2011.

—, L. Cavaleri, L. Loffredo, and L. Torrisi, 2013: Nettuno: Analysis of a wind and wave forecast system for the Mediterranean Sea. Mon. Wea. Rev., 141, 3130-3141, doi:10.1175/ MWR-D-12-00361.1.

- — A A. Soret, and R. Tolosana-Delgado, 2014: Performance of global and regional nested meteorological models. Cont. Shelf Sci., 87, 17-27, doi:10.1016/j.csr.2013.12.013.

Bidlot, J.-R., P. Janssen, and S. Abdalla, 2007: A revised formulation of ocean wave dissipation and its model impact. ECMWF Tech. Memo. 509, 27 pp. [Available online at http://old.ecmwf.int/ publications/library/ecpublications/_pdf/tm/501-600/tm509. pdf.]

Bromwich, D., Y. H. Kuo, M. Serreze, J. Walsh, L. S. Bai, M. Barlage, K. Hines, and A. Slater, 2010: Arctic System Reanalysis: Call for community involvement. Eos, Trans. Amer. Geophys. Union, 91, 13-14, doi:10.1029/2010EO020001.

Cavaleri, L., and L. Bertotti, 1997: In search of the correct wind and wave fields in a minor basin. Mon. Wea. Rev., 125, 1964-1975, doi:10.1175/1520-0493(1997)125<1964:ISOTCW > 2.0.CO;2.

- and - 2004: Accuracy of the modelled wind and wave fields in enclosed seas. Tellus, 56A, 167-175, doi:10.1111/ j.1600-0870.2004.00042.x.
Chen, F., and J. Dudhia, 2001: Coupling an advanced land surfacehydrology model with the Penn State-NCAR MM5 modeling system. Part I: Model description and implementation. Mon. Wea. Rev., 129, 569-585, doi:10.1175/1520-0493(2001)129<0569: CAALSH $>2.0 . \mathrm{CO} ; 2$.

Dudhia, J., 1989: Numerical study of convection observed during winter monsoon experiment using a mesoscale twodimensional model. J. Atmos. Sci., 46, 3077-3107, doi:10.1175/ 1520-0469(1989)046<3077:NSOCOD>2.0.CO;2.

Encyclopedia Britannica, 2008: Red Sea. Encyclopedia Britannica. [Available online at http://www.britannica.com/EBchecked/ topic/494479/Red-Sea.]

Garcia-Nava, H., F. J. Ocampo-Torres, P. Osuna, and M. A. Donelan, 2009: Wind stress in the presence of swell under moderate to strong wind conditions. J. Geophys. Res., 14, C12008, doi:10.1029/ 2009JC005389.

Gemmill, W., B. Katz, and X. Li, 2007: Daily real-time global sea surface temperature-High-resolution analysis: RTG_SST_HR NOAA/NWS/NCEP/MMAB Office Note 260, 39 pp. [Available online at http://polar.ncep.noaa.gov/mmab/papers/tn260/ MMAB260.pdf.]

Hong, S. Y., Y. Noh, and J. Dudhia, 2006: A new vertical diffusion package with an explicit treatment of entrainment processes. Mon. Wea. Rev., 134, 2318-2341, doi:10.1175/MWR3199.1.

Janssen, P. A. E. M., 1991: Quasi-linear theory of wind wave generation applied to wave forecasting. J. Phys. Oceanogr., 21, 1631-1642, doi:10.1175/1520-0485(1991)021<1631: QLTOWW $>2.0 . \mathrm{CO} ; 2$.

_ 2008: Progress in ocean wave forecasting. J. Comput. Phys., 227, 3572-3594, doi:10.1016/j.jcp.2007.04.029.

Jiang, H., J. T. Farrar, R. C. Beardsley, R. Chen, and C. Chen, 2009: Zonal surface wind jets across the Red Sea due to mountain gap forcing along both sides of the Red Sea. Geophys. Res. Lett., 36, L19605, doi:10.1029/2009GL040008.

Kain, J. S., and J. M. Fritsch, 1993: Convective parameterization for mesoscale models: The Kain-Fritsch scheme. The Representation of Cumulus Convection in Numerical Models, Meteor. Monogr., No. 46, Amer. Meteor. Soc., 165-170.

Lo, J. C. F., Z. L. Yang, and R. A. Pielke Sr., 2008: Assessment of three dynamical climate downscaling methods using the Weather Research and Forecasting (WRF) model. J. Geophys. Res., 113, D09112, doi:10.1029/2007JD009216.

Mlawer, E. J., S. J. Taubman, P. D. Brown, M. J. Iacono, and S. A. Clough, 1997: Radiative transfer for inhomogeneous atmospheres: RRTM, a validated correlated- $k$ model for the long wave. J. Geophys. Res., 102, 16663-16682, doi:10.1029/ 97JD00237.

Morcos, S. A., 1970: Physical and chemical oceanography of the Red Sea. Oceanogr. Mar. Biol. Rev., 8, 73-202.

Pielke, R. A., Sr., 2002: Mesoscale Meteorological Modeling. 2nd ed. Academic Press, 676 pp.

Ponce de Leon, S., and C. Guedes Soares, 2008: Sensitivity of wave model predictions to wind fields in the western Mediterranean Sea Coastal Eng., 55, 920-929, doi:10.1016/j.coastaleng.2008.02.023.

Ralston, D. K., H. Jiang, and T. F. Ferrar, 2013: Waves in Red Sea: Response to monsoonal and mountain gap winds. Cont. Shelf Res., 65, 1-13, doi:10.1016/j.csr.2013.05.017.

Richardson, D. S., J. Bidlot, L. Ferranti, T. Haiden, T. Hewson, M. Janousek, F. Prates, and F. Vitart, 2013: Evaluation of ECMWF forecasts, including 2012-2013 upgrades. ECMWF Tech. Memo. 710, 55 pp. [Available online at http://old.ecmwf. int/publications/library/ecpublications/_pdf/tm/701-800/tm710. pdf.] 
Skamarock, W. C., and Coauthors, 2008: A description of the Advanced Research WRF version 3. NCAR Tech. Note NCAR/TN-475+STR, 113 pp. [Available online at www. mmm.ucar.edu/wrf/users/docs/arw_v3 bw.pdf.]

Steele, C. J., S. R. Dorling, R. von Glasow, and J. Bacon, 2012: Idealized WRF model sensitivity simulations of sea breeze types and their effects on offshore wind fields. Atmos. Chem. Phys. Discuss., 12, 15837-15881, doi:10.5194/ acpd-12-15837-2012.

Steele, K. E., C. C. Teng, and D. W. C. Wang, 1992: Wave direction measurements using pitch and roll buoys. Ocean Eng., 19, 349375, doi:10.1016/0029-8018(92)90035-3.

Tolman, H. L., 1999: User manual and system documentation of WAVEWATCH-III version 1.18. NOAA/NWS/NCEP/OMB Tech. Note 106, 110 pp. [Available online at http://polar.ncep. noaa.gov/mmab/papers/tn166/OMB_166.pdf.]

- 2002: Validation of WAVEWATCH III version 1.15 for a global domain. NOAA/NWS/NCEP/OMB Tech. Note 213, 33 pp. [Available online at http://polar.ncep.noaa.gov/mmab/ papers/tn222/MMAB_222.pdf.]

, 2008: User manual and system documentation of WAVEWATCH III version 3.14. NOAA/NWS/NCEP/MMAB
Tech. Note 276, 220 pp. [Available online at http:// polar.ncep.noaa.gov/mmab/papers/tn276/MMAB_276.pdf.] , and D. V. Chalikov, 1996: Source terms in a third-generation wind wave model. J. Phys. Oceanogr., 26, 2497-2518, doi:10.1175/1520-0485(1996)026<2497:STIATG>2.0.CO;2.

Verhoef, A., and A. Stoffelen, 2013: Validation of ASCAT 12.5-km winds. Tech. Note SAF/OSI/CDOP/KNMI/TEC/RP/147, 11 pp. [Available online at http://www.knmi.nl/publications/ fulltexts/validation_of_ascat_12.5km_winds_1.3.pdf.]

Vogelzang, J., A. Stoffelen, A. Verhoef, and J. Figa-Saldana, 2011: On the quality of high-resolution scatterometer winds. J. Geophys. Res., 116, C10033, doi:10.1029/2010JC006640.

Waltham, T., 2005: Extension tectonics in the AFAR triangle. Geol. Today, 21, 101-107, doi:10.1111/j.1365-2451.2005.00510.x.

Yao, F., I. Hoteit, L. J. Pratt, A. S. Bower, P. Zhai, A. Köhl, and G. Gopalakrishnan, 2014a: Seasonal overturning circulation in the Red Sea: 1 . Model validation and summer circulation. J. Geophys. Res. Oceans, 119, 2238-2262, doi:10.1002/2013JC009004.

A. Köhl, G. Gopalakrishnan, and D. Rivas, 2014b: Seasonal overturning circulation in the Red Sea: 2. Winter circulation. J. Geophys. Res. Oceans, 119, 2263-2289, doi:10.1002/2013JC009331. 